\title{
Numerical Modeling of Air Pollutants and Greenhouse Gases Emissions in Intermodal Transport Chains
}

\author{
Mónica M. Ramalho and Tiago A. Santos * (D) \\ Centre for Marine Technology and Ocean Engineering (CENTEC), Instituto Superior Técnico, \\ University of Lisbon, 1049-001 Lisbon, Portugal; monicaramalho@tecnico.ulisboa.pt \\ * Correspondence: tiago.santos@centec.tecnico.ulisboa.pt
}

Citation: Ramalho, M.M.; Santos, T.A. Numerical Modeling of Air Pollutants and Greenhouse Gases Emissions in Intermodal Transport Chains. J. Mar. Sci. Eng. 2021, 9, 679 https://doi.org/10.3390/jmse9060679

Academic Editor: Claudio Ferrari

Received: 27 May 2021

Accepted: 16 June 2021

Published: 21 June 2021

Publisher's Note: MDPI stays neutral with regard to jurisdictional claims in published maps and institutional affiliations.

Copyright: (c) 2021 by the authors. Licensee MDPI, Basel, Switzerland. This article is an open access article distributed under the terms and conditions of the Creative Commons Attribution (CC BY) license (https:// creativecommons.org/licenses/by/ $4.0 /)$.

\begin{abstract}
This paper discusses the most attractive emission compliance options (emission abatement technologies and cleaner fuels) in intermodal transport chains that include short sea shipping. Most studies on emissions-based transport chain comparisons have estimated high levels of nitrogen and sulfur oxide emissions in maritime transportation, decreasing its competitiveness. However, the consequences of regulatory and technological developments and the integration of maritime transport in intermodal transport chains have not yet been considered in detail. In order to address this research gap, a numerical model for computing emissions from different transport modes in an intermodal transport network, under the effect of these developments, is presented that is based on bottom-up emission factors that depend on the fuel type, engine type, and operational profile of each vehicle. Different emissions scenarios are chosen for specific unimodal and intermodal routes (short sea shipping-based) between Portugal and northwestern Europe. Conclusions are drawn on estimated values of air pollutant emissions and greenhouse emissions, in $\mathrm{CO}_{2}$-eq per unit of cargo, in each scenario. These results allow the identification of the most environmentally friendly transport chains, thus supporting the development of adequate transport policies.
\end{abstract}

Keywords: freight transport emissions; short sea shipping emissions; modal shift; greenhouse gas emissions; sustainable transport

\section{Introduction}

The transport sector is responsible for around a quarter of greenhouse gas (GHG) emissions in Europe with road transport alone currently accounting for around 70\% of overall emissions [1]. In these last few years, the sector has not followed the general trend of GHG emissions. However, by 2050, the European Union (EU) needs its emissions to be cut by $80-95 \%$ below 1990 levels to reach the goal of limiting climate change to $2{ }^{\circ} \mathrm{C}$ [2]. As transport demand is further expected to grow, all transport modes are required to contribute to these emissions reductions, alleviating overall GHG emissions in Europe as set out in The European Green Deal [3]. At the same level, the National Emission Ceilings Directive [4] and the Gothenburg Protocol have set emission ceilings in the EU for sulfur oxides $\left(\mathrm{SO}_{\mathrm{x}}\right)$, nitrogen oxides $\left(\mathrm{NO}_{\mathrm{x}}\right)$, and particulate matter $(\mathrm{PM})$. The presence of those air pollutants has strongly decreased from 1990 levels due to stricter emission control instruments that led to fuel switching and the presence of new abatement equipment. Nevertheless, the transport sector still accounts for around half of the current $\mathrm{NO}_{\mathrm{x}}$ emissions in the EU, and road transport alone accounts for approximately 11\% of total fine PM emissions in the same region [5].

With those broad reduction targets in mind, the Transport 2050 Roadmap [6], along with the incentives for the use of alternative fuels and abatement technologies, has set as a goal to shift $30 \%$ of medium-distance intercity transport from road to other modes, such as rail or waterborne transport, by 2030 . In 2050 , that goal is set at $50 \%$ of current medium-distance road freight. The Green Deal [3] has now raised that target reduction 
to $75 \%$ of inland freight carried today by road to shift onto rail and inland waterways by 2050 . The modal shift from the road is expected to increase the competitiveness and sustainability of the transport system.

The rail and waterborne modes of transport, which include short sea shipping (SSS) and inland waterways (IWW), will assist the EU in attaining these objectives. However, rail and IWW networks of most peripheral countries in the EU are not as developed as in Central Europe and, in most cases, are not effectively interconnected with other regions of the EU. Simultaneously, many issues remain in terms of technical compatibility of railway lines and inland waterways in different countries. Therefore, for peripheral countries, SSS remains the most feasible alternative. On the other hand, SSS needs inevitably to be combined with other modes to complete full door-to-door transportation, and this is often done using intermodal transport units, be it containers, trailers, or swap bodies. Such units carry mostly general cargo, and it is for this type of cargo that SSS faces hard competition from road haulage. Bulk cargos are already mostly carried by sea or, if possible, using railway. This justifies the focus of this paper on studying and comparing transport emissions across intermodal transport chains running door-to-door.

Increasing the utilization of SSS depends on the relative performance of this mode of transportation in comparison with other modes. Its green reputation, in comparison with road transport, has been challenged by academics in recent years [7-9] due to the lagging performance of shipping in terms of reducing air pollution, for example due to the much higher sulfur content of maritime fuels in comparison with road diesel. However, a recent review of the research gaps about the modal shift from road to short sea shipping in the EU [10] points out that the use of abatement technologies and alternative fuels has been overlooked in most studies. Accordingly, the same review highlights the need for quantitative models that link emissions to cargo volumes in the light of the most recent fuel and emissions regulations and targets. The impact of shipping emissions on health and climate is well known and not overlooked [11]. A single, recent, example was found in a work that compares, quantitatively, three emission compliance options for the same case ship and operational route [12]. An earlier review on the state-of-the-art methodologies for estimating emissions from ships concludes that the limited availability of data has resulted in differing calculation methodologies of ship emissions, which are often not easy to compare, compromising the design and assessment of emission reduction strategies $[13,14]$. The application of those methods is present in papers dedicated to building ship emission inventories based on AIS data [15-18]. A further challenge for emissions-based modal comparison is the lack of real-world numerical data regarding emissions as well as of route-specific estimates based on the available emission factors.

This paper provides an update of the model to estimate emissions and external costs presented by the same authors [19] that allows for the simultaneous estimation of emissions, external and internal costs in transport corridors forming part of the Trans-European Transport Network (TEN-T). More accurate methods to estimate fuel consumption were introduced that, among other improvements, account for the effect of congestion in speed of road links and for changes in draught based on cargo utilization in maritime transport; the emission factors were revised and are now based on the most recent recommendations, reflecting the current impact of the use of new fuels and abatement technologies in all transport modes, particularly in maritime transport, making use of the significant progress made at IMO in the latest GHG study [20] in building accurate emission inventories. The model mentioned above has been implemented in a numerical tool from which results can also be used to promote and support the development by shipping companies of more fuel efficient, low-emissions, and sustainable transport chains.

The structure of this paper is as follows. In Section 2, the most attractive emission compliance options in intermodal transport chains are discussed. A particular focus is given to its compatibility with the most common types of marine engines used in short sea shipping vessels. In Section 3, a numerical model for computing emissions from different transport modes in an intermodal transport network is shown, which is based on bottom-up 
emission factors depending on the fuel type, engine type, and operational profiles of each vehicle. In Section 4, different emissions scenarios are chosen for specific unimodal and intermodal routes (short sea shipping based) between Portugal and north-western Europe, and numerical results for air pollutant emissions and greenhouse emissions, in $\mathrm{CO}_{2}$-eq per unit of cargo, in each scenario, are shown. Conclusions are presented in Section 5, focusing on the value of the developed tool and on the main findings of the case study.

\section{Emissions Control and Compliance Options}

\subsection{Emission Standards and Abatement Technologies in Land Transportation}

All transport modes have been contributing to an overall reduction in air pollutants compelled by stricter emission and fuel policies in the last decades. Those policies drive the development of fuel alternatives and emission abatement technologies that are widely available today. Action was first taken in road transport, with the EURO emissions standards for heavy-duty vehicles introduced in 1988 [21] and have become more stringent ever since. These are limit values expressed in $\mathrm{g} / \mathrm{kWh}$ for $\mathrm{NO}_{\mathrm{x}}$ and $\mathrm{PM}$ emissions that can be achieved by using diesel particulate filters (DPFs) or other emission abatement technologies such as selective catalytic reduction (SCR). This has been common practice among engine and truck manufacturers in the EU. Currently, the EURO VI standard is implemented. It is also required to comply with the Fuel Quality Directive 2009/30/EC [22] currently limiting the sulfur content of road fuels at $10 \mathrm{ppm}$. Nevertheless, today, road freight transport still accounts for close to $30 \%$ of global $\mathrm{CO}_{2}$ emissions from transport. In June 2019, the first carbon dioxide emission performance standards were introduced for heavy duty vehicles (HDVs) in Regulation 2019/1242 [23]. It sets $\mathrm{CO}_{2}$ tailpipe emissions reduction factors for manufacturers based on current fleet size and characteristics, forcing the fleet to gradually change into zero emission vehicles such as electric. In this sense, with its close to $25 \%$ lower carbon content, liquefied natural gas (LNG) can be a good transition alternative fuel for road haulage in some areas. Currently, in Germany, there is an example of an incentive for transition with LNG and CNG-powered trucks being exempted from motorway tolls.

Standards for emissions of engines used in non-road mobile machinery such as trains were introduced in Directive 97/68/EC [24] and are also becoming more stringent. The Stage III-IV standard is currently adopted for engines used for the propulsion of rail locomotives and specifies, in $\mathrm{g} / \mathrm{kWh}$, limits for $\mathrm{NO}_{\mathrm{x}}$ and $\mathrm{PM}$ emissions. The limits have been met with the development of new engines and the use of DPFs and $\mathrm{NO}_{\mathrm{x}}$ after treatment systems. A new Stage V standard is soon to be adopted. The technical specifications for fuels used in rail engines are also set in the Fuel Quality Directive [22]. Rail transport is today the most electrified, low-carbon, mode in Europe. However, rail freight transport mostly uses diesel locomotives due to the low return of investment in electrifying secondary low-traffic lines where those trains usually run.

\subsection{Emission Standards and Abatement Technologies in Water Transportation}

Maritime and inland waterway transportation has also devoted attention to reducing emissions, although with some delay in comparison with the other modes of transportation. As a significant part of freight is indeed carried by the sea and river in the EU, understanding the options to cut emissions from ships is important to help define which fuel alternatives and/or technologies can and must be used depending on the service type and route. In fact, air pollution from shipping can also have a substantial impact on human health because $70 \%$ of ship emissions occur within $400 \mathrm{~km}$ of land [25]. Regarding $\mathrm{NO}_{\mathrm{x}}$ emissions, MARPOL Annex VI defines limits for compliance on $\mathrm{NO}_{\mathrm{x}}$ emissions from large marine diesel engines (130 kW or larger) using the Tier I, Tier II, and Tier III standards. The designation of Emission Control Areas (ECAs) is also included in Annex VI. The current global standard from IMO Tier II limits the emissions to 7.7-14.4 $\mathrm{g}$ of $\mathrm{NO}_{\mathrm{x}} / \mathrm{kWh}$. The stricter Tier III $\mathrm{NO}_{x}$ standard of a maximum of 2-3.4 $\mathrm{g}$ of $\mathrm{NO}_{\mathrm{x}} / \mathrm{kWh}$ will apply to new ships built after 2021 only when sailing in $\mathrm{NO}_{\mathrm{x}}$ Emission Control Areas (NECAs). In the EU, 
Directive EU 2016/802 [26] implements the 2020 global sulfur limit $0.50 \% \mathrm{~m} / \mathrm{m}$ on-board ships. Within SECAs, the sulfur content of marine fuels must not exceed $0.10 \%$. At berth, ships in Union ports must not use marine fuels with a sulfur content exceeding $0.10 \%$ by mass except if the ships are due to be at berth for less than $2 \mathrm{~h}$ or all engines are switched off. If an equivalent level of emissions is met using fuels with other sulfur content, emission abatement methods may be always used as an alternative to fuel switch.

Emission limits for engines used in inland waterway vessels were first introduced in 2002 specifically for navigation on the Rhine by the Central Commission for the Navigation of the Rhine (CCNR) [27] but are now generally fixed by regulation (EU) 2016/1628, as for rail engines, repealing the aforementioned directive [24]. CCNR-1 had limits similar to the Tier I from MARPOL, and current engines comply with CCNR-2 standards that are close to the Stage III EU standards of 6.0-11.0 $\mathrm{g} \mathrm{NO}_{\mathrm{x}} / \mathrm{kWh}$ and $0.2 \mathrm{~g}$ PM/kWh [26]. As of 1 January 2021, for an engine with a net power greater than $300 \mathrm{~kW}$, very tight emission limits of $1.80 \mathrm{~g} \mathrm{NO}_{\mathrm{x}} / \mathrm{kWh}$ and $0.015 \mathrm{~g} \mathrm{PM} / \mathrm{kWh}$ apply under Stage $\mathrm{V}$ regulation. Moreover, under the Fuel Quality Directive [22], as for road and rail fuels, only very low-sulfur fuels with a maximum content of $0.001 \%$ can be used.

At sea, fuel switch is the primary emissions compliance technique, but it is not always possible. $\mathrm{SO}_{\mathrm{x}}$ compliance options include the use of low sulfur fuels (MDO, MGO, LSHFO, VLSFO, ULSFO), reducing the emissions at source. Low sulfur distillate oils are usually marine diesel oil (MDO, a blend of distillate and heavy fuel oil) or marine gas oil (MGO) [28]. LSHFO is residual marine fuel with sulfur content of $1 \%$. The so-called VLSFO and ULSFO can be either distillates or residuals with a maximum of $0.5 \%$ and $0.1 \%$, respectively. A popular alternative is the use of LNG, which is a sulfur-free fuel. According to IMO GHG 2020 [20], all types of HFO should be preferably replaced with MDO $(0.1 \%)$ in the vessel's main engine, auxiliary engine, and boiler when entering an ECA. $\mathrm{NO}_{x}$ emissions are created during the combustion process and depend on the fuel being used as well as on the engine design.

It is also important to take in consideration that not all fuel types are compatible with existing marine engines, and Table 1 clarifies this compatibility. Marine diesel engines are either two-stroke cycle or four-stroke cycle and depending on the rotational velocity either slow speed (SS, up to $400 \mathrm{rpm}$ ), medium speed (MS, 400-1200 rpm), or high speed (HS, above $1200 \mathrm{rpm}$ ) [29]. Slow speed engines are typically two-stroke and optimised to operate on heavy fuel oil (lower viscosity and better lubricity), but many diesel engines can be converted to dual-fuel operation switching from gas to diesel and vice versa. Gas engines can be pure gas or dual-fuel and then categorized by the combustion cycle (Diesel or Otto). LNG can be used in pure gas four-stroke medium and high-speed engines, dual-fuel fourstroke medium-speed engines, and dual-fuel two-stroke slow-speed engines. Methanol can be used mainly in two-stroke diesel-cycle engines or four-stroke pure gas engines [30]. In short-sea shipping, dual-fuel engines are generally four-stroke medium-speed engines.

Table 1. Compatibility between types of marine engines and different fuels.

\begin{tabular}{|c|c|c|c|c|c|}
\hline & Methanol & LNG & MDO & HFO & LSHFO \\
\hline SS 2-Stroke Diesel & $x$ & $x$ & $x$ & $\checkmark$ & $\checkmark$ \\
\hline MS 4-Stroke Diesel & $x$ & $x$ & $\checkmark$ & $\checkmark$ & $\checkmark$ \\
\hline HS 4-Stroke Diesel & $x$ & $x$ & $\checkmark$ & $\checkmark$ & $\checkmark$ \\
\hline 4-Stroke Dual-fuel & $x$ & $\checkmark$ & $\checkmark$ & $\checkmark$ & $\checkmark$ \\
\hline 4-Stroke Gas only & $\checkmark$ & $\checkmark$ & $x$ & $x$ & $x$ \\
\hline SS 2-Stroke Dual-fuel & $\checkmark$ & $\checkmark$ & $\checkmark$ & $\checkmark$ & $\checkmark$ \\
\hline
\end{tabular}

Apart from fuel switch techniques, the emission abatement technologies for which impact on emissions is quantified include exhaust gas treatment systems such as Diesel Particulate Filters (DPF) and Wet (using sea water-SWS—or fresh water-FWS) or Dry Scrubbers; Selective Catalyst Reduction (SCR); Exhaust Gas Recirculation (EGR); Humid Motor Air System (HAM); Water in Fuel (WIF). Further details on these systems may be 
found in Appendix A. Table 2 presents the emission reduction factors granted by these technologies in comparison with the emissions with no emission abatement technology.

Table 2. Emission and fuel consumption changing factors of abatement technologies [29,30].

\begin{tabular}{cccccc}
\hline Reducing Technology & $\mathbf{N O}_{\mathbf{x}}$ & $\mathbf{S O}_{\mathbf{x}}$ & $\mathbf{P M}$ & $\mathbf{C O}_{\mathbf{2}}$ & Fuel Consumption \\
\hline DPF & - & - & $-75 \%$ & - & $+1 \%$ \\
SWS/FWS & - & $-97 \%$ & $-60 \%$ & - & $+5 \%$ \\
SCR & $-90 \%$ & - & - & - & - \\
EGR, based on Tier II & $-80 \%$ & $+2 \%$ & $+2 \%$ & $+2 \%$ & $-2 \%$ \\
SWS/FWS + EGR & $-80 \%$ & $-97 \%$ & $-60 \%$ & - & - \\
HAM (Humid Air Motor) System & $-65 \%$ & - & - & - & $+2 \%$ \\
WIF-Water in Fuel (50\%) & $-50 \%$ & $+2 \%$ & $+2 \%$ & $+2 \%$ & - \\
\hline
\end{tabular}

Integrating these technologies with each other for the simultaneous reduction of $\mathrm{SO}_{\mathrm{x}}$, $\mathrm{NO}_{\mathrm{x}}$, and/or PM emissions is possible, as well as connecting multiple exhaust channels to the same scrubber or particulate filter unit [28]. However, the combination of the most popular solution for $\mathrm{SO}_{x}$ reduction - wet scrubbing —with the most popular solution for $\mathrm{NO}_{x}$ reduction-SRC - is only possible with additional requirements. SCR needs high temperatures of the exhaust gas, which means that it must be installed before the scrubber. On the other hand, it is not suitable for operating in the exhaust of higher sulfur content fuels. This means that simply the combination of these well-known systems when using conventional fuel oil is not straightforward. One of the solutions to this problem is to reheat the exhaust gas after scrubbing before SCR, but that results in high additional expenses $[28,31]$. Tables 3 and 4 summarize the compatibility of those emission abatement technologies with the most common marine engine types and fuels.

Table 3. Emissions abatement technologies integration with different engine types.

\begin{tabular}{|c|c|c|c|c|c|c|}
\hline & $\begin{array}{c}\text { SS } \\
\text { 2-Stroke } \\
\text { Diesel }\end{array}$ & $\begin{array}{c}\text { MS } \\
\text { 4-Stroke } \\
\text { Diesel }\end{array}$ & $\begin{array}{c}\text { HS } \\
\text { 4-Stroke } \\
\text { Diesel }\end{array}$ & $\begin{array}{c}\text { 4-Stroke } \\
\text { Dual-Fuel }\end{array}$ & $\begin{array}{c}\text { 2-Stroke } \\
\text { Dual-Fuel }\end{array}$ & $\begin{array}{l}\text { 4-Stroke } \\
\text { Gas Only }\end{array}$ \\
\hline DPF & $\checkmark$ & $\checkmark$ & $\checkmark$ & $\checkmark$ & $\checkmark$ & $x$ \\
\hline WS (Wet Scrubbing) & $\checkmark$ & $\checkmark$ & $\checkmark$ & $\checkmark$ & $\checkmark$ & $x$ \\
\hline DS (Dry Scrubbing) & $\checkmark$ & $\checkmark$ & $\checkmark$ & $\checkmark$ & $\checkmark$ & $x$ \\
\hline SCR & $!$ & $\checkmark$ & $\checkmark$ & $\checkmark$ & $!$ & $\checkmark$ \\
\hline EGR, based on Tier II & $\checkmark$ & $?$ & $?$ & $?$ & ? & $?$ \\
\hline $\begin{array}{l}\text { HAM (Humid Air } \\
\text { Motor) }\end{array}$ & ? & $\checkmark$ & $\checkmark$ & $?$ & ? & $x$ \\
\hline $\begin{array}{c}\text { WIF_-Water in Fuel } \\
(50 \%)\end{array}$ & $\checkmark$ & $!$ & $!$ & $x$ & $x$ & $x$ \\
\hline
\end{tabular}

Table 4. Emissions abatement technologies integration when different fuels are used.

\begin{tabular}{|c|c|c|c|c|c|}
\hline & HFO $(2.6 \% \mathrm{~S})$ & LSHFO (1\% S) & $\operatorname{MDO}(0.1 \% \mathrm{~S})$ & LNG & $\mathrm{MeOH}$ \\
\hline DPF & $\checkmark$ & $\checkmark$ & $\checkmark$ & $x$ & $x$ \\
\hline WS (Wet Scrubbing) & $\checkmark$ & $\checkmark$ & $\checkmark$ & $x$ & $x$ \\
\hline DS (Dry Scrubbing) & $\checkmark$ & $\checkmark$ & $\checkmark$ & $x$ & $x$ \\
\hline SCR & $!$ & $!$ & $\checkmark$ & $\checkmark$ & $\checkmark$ \\
\hline EGR, based on Tier II & $!$ & $!$ & $\checkmark$ & $?$ & $?$ \\
\hline HAM (Humid Air Motor) & $\checkmark$ & $\checkmark$ & $\checkmark$ & $x$ & $x$ \\
\hline WIF-Water in Fuel (50\%) & $\checkmark$ & $\checkmark$ & $!$ & $x$ & $x$ \\
\hline
\end{tabular}

Key: $\boldsymbol{\checkmark}$-Tested, ?-Under consideration, $\boldsymbol{X}$-Not considered/applicable, !—Possible with additional requirements.

\section{Numerical Model of Transport Emissions}

A numerical model was formulated to estimate the actual quantity of pollutant emissions in an intermodal voyage through the calculation of the vehicle's fuel consumption combined with emission factors and the utilization of abatement technologies. This is done for all transport modes considering that either engine load or consumption characteristics and fuel are known, and emission factors or vehicle compliance standards are available. 
This numerical model, described in Section 3.2, has been implemented in a numerical research tool called Sustainability Analyst (SA), which is supported by a transportation network model, as described in Section 3.1.

\subsection{Transport Network Model}

The transport network model based on the TEN-T and built in this research group covers the geographical region comprised between Portugal and northwestern Europe. It is an intermodal transportation network accounting for four different modes of transportation: road, rail, inland waterways, and short sea shipping. The nodes and links form an extensive database (over 3000 nodes and 4000 links) along with its relevant node-specific and linkspecific characteristics for the calculation of transport emissions, internal costs, transit time, and external costs of transportation. This paper is focused primarily on the emissions originating from intermodal voyages carried out along this network. The objective is to evaluate the impact of different fuel types and emission abatement technologies in the amount of emissions originating from different transport chains.

The numerical model allows studies of emissions to be carried out for any pair of origin and destination (O/D) included in the network, using different intermodal transport chains (depending on existing infrastructure), differing mainly in the combination of modes of transportation. Each transport chain is modeled by a path $\mathrm{j}$ between the relevant combination $i$ of origin/destination, the path being defined by the user using suitable sequences of node numbers. The numerical tool identifies the succession of links $\mathrm{k}$ connecting the different nodes and the type (road, rail, IWW, SSS) of each link. The emissions from transport over a given path are calculated on a link-specific basis, using the model detailed below in Section 3.2, and then added up each transport mode. The relevant link characteristics that can be found in the database for the calculation of emissions and results allocation include the traveled distance and speed within each link, the type of road (motorway or others), or emission zone (inside/outside ECA).

For each path, the vehicles used in the various transport modes are defined in terms of their technical characteristics. The user must specify characteristics and values suitable for each variable according with the format contained in Table S1 (Supplementary Materials) in an input file for the numerical tool where the method is implemented. The unit of cargo used is a trailer, with dimensions and weight considered roughly equivalent to a forty-feet equivalent unit container (FEU). The truck weight is approximated to the trailer weight for simplification.

\subsection{Modeling Transport Modes Emissions}

For each mode, the most common fuel consumption estimation methods from the literature were analyzed, and the following model describes the application of those methods using the path and vehicle details from the transportation network and input files, respectively.

\subsubsection{Waterborne Transport Emissions}

The vessel's fuel consumption is calculated including those of the main engines, auxiliary engines, and boiler (if any). For each engine, the fuel consumption is a function of the power demand and the specific fuel consumption SFC. For the vessel's main engine, the fuel consumption $F C_{M E}$ per link, in g-ship, can be calculated, for each link $k$ part of path $j$ and pair origin/destination $i$, according to Equation (1), which depends on the engine power demand $P_{E F}$, in $\mathrm{kW}$, on the specific fuel consumption of the main engine $S F C_{M E}$, in $\mathrm{g} / \mathrm{kWh}$, on the vessel's speed in the link, SSpeed $_{i j k}$, in $\mathrm{km} / \mathrm{h}$ and on the link's length LDist $_{i j k}$ in $\mathrm{km}$ :

$$
F C_{M E, i j k}=S F C_{M E} \times P_{E F} \times \frac{\text { LDist }_{i j k}}{\text { LSpeed }_{i j k}}
$$

The engine power demand is calculated adjusting for speed and draught. This way, it is possible to account for the effects of speed and load capacity utilization in each link. 
The draft of the ship $D_{i j k}$ is estimated by computing the variation of deadweight with the number of cargo units onboard. The weight of one cargo unit is given by variable $W F E U_{i j}$, and so the variation of deadweight can be calculated at each link:

$$
\delta \Delta=\text { Sss Dead }_{i j}-\text { WFEU }_{i j} \times S_{s s C a p} \operatorname{Cos}_{i j} \times \text { ssUt }_{i j}
$$

Using an estimated water plane area coefficient, $c_{w}$ of 0.671 and 0.740 for Ro-Ro [32] and container ships [33], respectively, and using the main dimensions of the ship-length between perpendiculars, breadth, and design draught, respectively-through variables $S s s p p_{i j}, S_{s s} B_{i j}$, and $S s s D_{i j}$, the new corresponding draft can be calculated:

$$
\begin{gathered}
\delta \Delta=A_{w} \times \delta i \times \gamma \Leftrightarrow \delta i=\frac{\delta \Delta}{A_{w} \times \gamma} \\
c_{w}=\frac{A_{w}}{L_{f} \times B_{f}} \Leftrightarrow A_{w}=c_{w} \times L_{f} \times B_{f} \\
D_{i j k}=S s s D_{i j}-\delta i
\end{gathered}
$$

The following equation can be used to estimate the SFC at different engine loads of internal combustion engines:

$$
S F C_{M E, i}=S F C_{\text {base }} \times\left(0.455 \times \operatorname{Load}_{i}^{2}-0.710 \times \operatorname{Load}_{i}+1.280\right)
$$

Load $_{i}$ is the main engine loading ratio from zero to one. The specific fuel consumption $S F C_{\text {base }}$ is expressed in $\mathrm{g} / \mathrm{kWh}$ for different engine and fuel types at the most fuel-efficient point (around 80\% MCR) [20]. All engines are considered third-generation engines build after the year 2000. For residual low-sulfur fuels (LSHFO, VLSFO, and ULSFO), the $S F C_{\text {base }}$ is the same as for HFO.

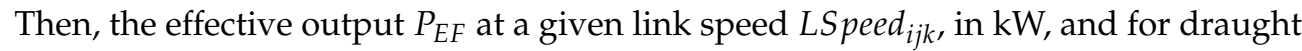
$D_{i j k}$, in $\mathrm{m}$, can be estimated using Equation (7) [20]:

$$
P_{E F, i j k}=\frac{\operatorname{SssPME}_{i j} \times\left(\frac{\text { LSpeed }_{i j k}}{\text { SssSpeed }_{i j} \times 1.852}\right)^{3} \times\left(\frac{D_{i j k}}{\operatorname{Sss}_{i j}}\right)^{0.66}}{\eta_{w} \times \eta_{f}}
$$

where $S_{S S P M E}$ is the installed main engine power and SsSSpeed $i j$ is the ship's speed, in knots, at $100 \%$ of maximum continuous rating (MCR) with clean hull and calm sea. The denominators $\eta_{w}$ and $\eta_{f}$ represent the weather and fouling effects of the ship's propulsive efficiency. $\eta_{w}$ is 0.909 for containerships carrying less than 1000 TEUs and 0.867 for Ro-Ro of more than 5000 DWT. $\eta_{f}$ is 0.917 for all ship types and sizes [20].

Similarly, the fuel consumption in $\mathrm{g}$ of the $\mathrm{n}$ auxiliary engines can be calculated as follows in Equation (8), depending on the time and engine power demand at sea in $\mathrm{kW}$. By assumption, auxiliary engines' specific fuel consumption is not dependent on their load [20], and so $S F C_{A E}$ is assumed constant:

$$
F C_{A E, i j k}=S F C_{A E} \times E F \times S s S P A E_{i j} \times n \times \frac{L_{\text {Dist }}^{i j k}}{\text { LSpeed }_{i j k}}
$$

Assumptions on engine load for the different operational activities [34] are used to estimate the auxiliary engine power demand. For example, the auxiliary engine load (EL) at sea is assumed to be $30 \%$ of engine MCR $(E L=0.3)$ as per Table 5 . When the calculated main engine load is below $20 \%$, the vessel is assumed to be in the maneuvering profile, and in that case, the auxiliary engine power demand is set to $50 \% \mathrm{MCR}$ instead of $30 \%$ at sea. 
Table 5. Main and auxiliary engines power demands at different operation profiles.

\begin{tabular}{cccc}
\hline & $\begin{array}{c}\text { \% Load of MCR for } \\
\text { ME Operation }\end{array}$ & $\begin{array}{c}\text { \% Of Time All MEs } \\
\text { Operating }\end{array}$ & $\begin{array}{c}\text { \% Load of MCR for } \\
\text { AE Operation }\end{array}$ \\
\hline at sea & 80 & 100 & 30 \\
in port & 20 & 5 & 40 \\
maneuvering & 20 & 100 & 50 \\
\hline
\end{tabular}

In the new IMO GHG Study [20], exhaust emissions are calculated according with the most common method for each pollutant: for $\mathrm{NO}_{\mathrm{x}}$ and $\mathrm{PM}$ based on energy emission factors in $\mathrm{g} / \mathrm{kW}$; for $\mathrm{CO}_{2}$-eq and $\mathrm{SO}_{2}$ based on fuel emission factors in $\mathrm{g} / \mathrm{g}$.

The conversion factors from mass of fuel to mass of $\mathrm{CO}_{2}$ emitted are available in the IMO GHG Study. For low sulfur residual fuels, the same carbon content of HFO is assumed. To calculate the emission factors of $\mathrm{CO}_{2}$-eq equivalents, the global warming potential of each main GHG $\left(\mathrm{CO}_{2}, \mathrm{CH}_{4}\right.$ and $\left.\mathrm{N}_{2} \mathrm{O}\right)$ is multiplied by its emission factors available in the IMO GHG Study [35].

$\mathrm{SO}_{2}$ emission factors depend on the fuel sulfur content and can be calculated according with the formula, in $\mathrm{g} / \mathrm{g}$ fuel:

$$
E F_{S O_{2, i j}}=\frac{S C_{i j}}{10^{6}} \times 0.97753 \times \frac{(32+16+16)}{32}=\frac{S C_{i j}}{10^{6}} \times 0.97753 \times 2
$$

where $S C$ is in ppm weight, and it is assumed that $97.753 \%$ of the fuel sulfur is converted to $\mathrm{SO}_{2}$ [36]. The remaining factor is the molecular weight relation of $\mathrm{SO}_{2}$.

The new IMO GHG study highlights the distinction between $\mathrm{PM}_{10}$ and $\mathrm{PM}_{2.5}$, assuming that $92 \%(\mathrm{~m} / \mathrm{m})$ of calculated $\mathrm{PM}_{10}$ is $\mathrm{PM}_{2.5}$. The $\mathrm{PM}_{10}$ emission factor is a function of the fuel's sulfur content as per the following equations for, respectively, HFO and MDO/MGO:

$$
\begin{aligned}
& E F_{e P M 10}=1.35+S F C_{i j} \times 7 \times 0.02247 \times(S-0.0246) \\
& E F_{e P M 10}=0.23+S F C_{i j} \times 7 \times 0.02247 \times(S-0.0024)
\end{aligned}
$$

Using Equation (10) above, where $S$ is the fuel sulfur content ratio, the emission factors for LSHFO, VLSFO, and ULSFO are calculated. For pure LNG and auxiliary engines, the emission factor is $0.02 \mathrm{~g}$ of $\mathrm{PM}_{10}$ per $\mathrm{kWh}$.

For $\mathrm{NO}_{\mathrm{x}}$, the tier emission limits are used as emission factors. The standard that the engine complies with is specified in variable $S_{s s T i e r}{ }_{i j}$.

To convert $\mathrm{NO}_{\mathrm{x}}$ and $\mathrm{PM}$ energy-based emission factors in $\mathrm{g} / \mathrm{kW}$ to fuel-based emission factors in $\mathrm{g} / \mathrm{g}$, the $S F C_{\text {base }}$ is used:

$$
E F_{f}=\frac{E F_{e}}{S F C_{\text {base }}}
$$

$\mathrm{NO}_{\mathrm{x}}$ and $\mathrm{PM}$ emission factors are also a function of the engine load but can be considered constant above $20 \%$ MCR. When the engine load is below $20 \% \mathrm{MCR}$, the emission factors increase due to lower combustion efficiency. Adjustment factors that represent this change are included [20] and applied only to the main engine because the auxiliary engine load is assumed greater than $20 \%$ in all operational profiles. $\mathrm{SO}_{2}$ and $\mathrm{CO}_{2}$ emission factors vary directly as a function of fuel consumption and engine load.

Emissions in port are calculated through fuel consumption during the number of hours spent in port at each Ro-Ro or container terminal-TPort ${ }_{i j}$ - at an auxiliary engine load of $40 \%$ of MCR as per Table 5 .

$$
F C_{A E, \text { Port }}=S F C_{A E} \times 0.4 S s S P A E_{i j} \times \text { TPort }_{i j}
$$

This model also includes the effects of emission abatement technologies, if any are used. Such technologies may be used for the main and/or auxiliary engines outside and/or 
inside ECA zones. In those cases, the factors in Table 2 apply: first on fuel consumption and then through emissions computations.

The amount of emissions per pollutant at each link $k$ of path $j$ between an origin and destination set $i$, and the emissions at port within each path, is obtained by multiplying the fuel consumption by the emission factors in $\mathrm{g} / \mathrm{g}$ fuel as per Equations (14)-(17). Emissions per trailer are computed by dividing total emissions per link or path by the vessel's freight capacity in number of trailers $S s s C a p_{i j}$ and its capacity utilization factor $S s s U t_{i j}$.

$$
\begin{gathered}
g C O_{2, i j k}-e q=F C_{M E, i j k} \times e f_{C O-e q_{2} M E}+F C_{A E, i j k} \times e f_{C O-e q_{2} A E} \\
g S O_{X, i j k}=F C_{M E, i j k} \times e f_{S O_{X} M E}+F C_{A E, i j k} \times e f_{S O_{X} A E} \\
g N O_{X, i j k}=F C_{M E, i j k} \times e f_{N O_{X} M E}+F C_{A E, i j k} \times e f_{N O_{X} A E} \\
g P M_{i j k}=F C_{M E, i j k} \times e f_{P M M E}+F C_{A E, i j k} \times e f_{P M A E}
\end{gathered}
$$

Regarding inland waterway transport, the fuel consumption of the main engine $F C_{M E}$ is modeled by (18) in g per vessel, and the fuel consumption of the auxiliary engine is assumed to be $5 \%$ of that value [37].

$$
F C_{M E, i j k}=\frac{S F C_{I W W} \times P_{E}}{L_{S p e e d}} \times \text { LDist }_{i j k}
$$

The specific fuel consumption of the main engine $S F C_{I W W}$ is taken from the IMO GHG Study [20] depending on the engine speed rating — Iww Rating $g_{i j}$ - and fuel_IwwFuel ${ }_{i j}$ and on fuel for the auxiliary engine. The effective power of the main engine $P_{E}$ is calculated by Equation (19), neglecting hydrodynamic effects, where IwwPME $E_{i j}$ is the inland vessel's installed main engine power in $\mathrm{kW}$, and Iww Speed $_{i j}$ is its speed in knots at $100 \% \mathrm{MCR}$ :

$$
P_{E, i j k}=I w w P M E_{i j} \times\left(\frac{\text { LSpeed }_{i j k}}{\text { IwwSpeed }_{i j} \times 1.852}\right)^{3}
$$

The choice of fuel can be either very-low sulfur diesel with $0.001 \%$ sulfur content or LNG. For each of those fuels, the PM emission factors used are calculated from the sulfur content using Equation (11).

CCNR Stages I and II and EC Stage V limits [22] are used as emission factors when computing $\mathrm{NO}_{\mathrm{x}}$ emissions. The standard that the engine complies with is specified in the variable IwwStage $e_{i j}$. All emission abatement technologies mentioned in Table 2 can be used and combined through variable $I w w E A T_{i j}$ for the main engine, whenever the engine is not compliant with Stage $\mathrm{V}$ emission limits. In current diesel engines, it implies the use of a particulate filter and $\mathrm{NO}_{\mathrm{x}}$ trap or SCR device.

The quantity of emissions per pollutant is obtained by multiplying the fuel consumption by the emission factors in $\mathrm{g} / \mathrm{g}$ fuel-Equations (14)-(17). As mentioned before, assuming that $92 \%(\mathrm{~m} / \mathrm{m})$ of calculated $\mathrm{PM}_{10}$ is $\mathrm{PM}_{2.5}$, emissions per trailer are computed by dividing the total emissions per link or path by the vessel's freight capacity in number of trailers $I w w C a p_{i j}$ and its capacity utilization factor IwwUt $t_{i j}$.

\subsubsection{Road Transport Emissions}

For road transport, current regulated main emissions include $\mathrm{NO}_{\mathrm{x}}$ and $\mathrm{PM}$. EURO emission standards are used in $\mathrm{g} / \mathrm{kWh}$, and it is assumed that for road vehicles, $90 \%$ of $(\mathrm{m} / \mathrm{m})$ of calculated $\mathrm{PM}_{10}$ is $\mathrm{PM}_{2.5}$. For the calculation of non-regulated emissions of $\mathrm{CO}_{2}$, the carbon content of the fuel is used, and the emission factors in $\mathrm{g} / \mathrm{g}$ for different transport fossil fuels are available in the Environment Agency Emission Inventory Guidebook [38]. For diesel, the $\mathrm{CO}_{2}$ emission factor is $3.169 \mathrm{~g} / \mathrm{g}$ and $2.743 \mathrm{~g} / \mathrm{g}$ for LNG, and it can be 
converted into $\mathrm{g} / \mathrm{kWh}$ using the specific fuel consumption value of the truck's engine in $\mathrm{g} / \mathrm{kWh}$ stored in the input variable $\operatorname{TruSFOC}_{I J}$ :

$$
E F_{\mathrm{CO}_{2}}\left[\frac{g}{k W h}\right]=E F_{\mathrm{CO}_{2}}\left[\frac{g}{g}\right] \times \operatorname{TruSFOC}_{i j}
$$

To calculate the emission factors of $\mathrm{CO}_{2}$-eq, the global warming potential of each main GHG $\left(\mathrm{CO}_{2}, \mathrm{CH}_{4}\right.$, and $\left.\mathrm{N}_{2} \mathrm{O}\right)$ is multiplied by its emission factors. For diesel, the $\mathrm{CO}_{2}$-eq emission factor is $3.181 \mathrm{~g} / \mathrm{g}$ and $3.104 \mathrm{~g} / \mathrm{g}$ for LNG. As for $\mathrm{SO}_{2}$, the emission factor in $\mathrm{g}$ $\mathrm{SO}_{2} / \mathrm{g}$ fuel can be calculated according with Equation (9). The emission factor of $\mathrm{SO}_{2}$ for road vehicles can also be converted into $\mathrm{g} / \mathrm{kWh}$ using the specific fuel consumption of the truck's engine in $\mathrm{g} / \mathrm{kWh}$ following Equation (12).

Regarding LNG, emission factors match EURO V and EURO VI standards with a further reduction in the $\mathrm{SO}_{2}$ emissions that depends on the fuel sulfur content (3.5 ppm) [37]. This way, LNG fueled trucks' emissions can be estimated.

The power demand $P_{D}$ from the truck engine in each link traveling at constant speed is calculated as below, where $F_{T}$ is the total of the resistance forces acting on the truck in $\mathrm{N}$ and $\eta$ is the overall transmission efficiency-the ratio of delivered power to shaft power assumed constant at 0.85 :

$$
P_{D}=\frac{F_{T}}{\eta} \times \frac{\text { LSpeed }_{i j k}}{3.6}
$$

The resistance acting on the truck can be estimated as the sum of the aerodynamic drag $F_{d}$ and rolling resistance $F_{r}[39]$.

$$
\begin{aligned}
F_{T}=F_{d}+F_{r}=\frac{1}{2} & \times C_{d} \times \rho \times A \times\left(\frac{\text { LSpeed }_{i j k}}{3.6}\right)^{2}+c \times \text { TruClass }_{i j} \times 10^{3} \times 9.81 \\
& =0.28 \times \text { LSpeed }_{i j k}{ }^{2}+58.86 \times \text { TruClass }_{i j}
\end{aligned}
$$

$C_{d}$ is the drag coefficient, $\rho$ is the air resistance, and $A$ is the frontal area of the truck in $\mathrm{m}^{2} . C_{d} \cdot A$ takes the value of $6 \mathrm{~m}^{2}$ and $\rho$ is $1.225 \mathrm{~kg} / \mathrm{m}^{3} . c$ is the rolling resistance coefficient and takes the value of 0.006, TruClass $_{i j}$ is the gross weight of the truck in tonnes and the remaining acceleration of gravity.

The change in speed due to congestion and its impact on the travel time and fuel consumption may be considered as a user preference in the numerical tool. Each link in the network is assigned a congestion level based on the traffic volume and the theoretical road capacity ratio as defined in Table 6 [40]. Using approximate values from the speed-flow relationship, a speed reduction factor is multiplied by the link speed $L S p e e d_{i j k}$ in all the above formulations when a link is affected by one of the more severe levels of congestion.

Table 6. Congestion level and speed reduction in road links.

\begin{tabular}{ccc}
\hline Congestion Level & Volume/Capacity Ratio (v/c) & $\begin{array}{c}\text { Speed Reduction (from } \\
\text { Speed-Flow Relationship Graph) }\end{array}$ \\
\hline 1 & $\mathrm{v} / \mathrm{c}<0.4$ & $1 \times \mathrm{v} 0$ \\
2 & $0.4<\mathrm{v} / \mathrm{c}<0.8$ & $1 \times \mathrm{v} 0$ \\
3 & $0.8 \geq \mathrm{v} / \mathrm{c}>1$ & $0.75 \times \mathrm{v} 0$ \\
4 & $1 \geq \mathrm{v} / \mathrm{c}>1.2$ & $0.5 \times \mathrm{v} 0$ \\
5 & $\mathrm{v} / \mathrm{c} \geq 1.2$ & $0.4 \times \mathrm{v} 0$ \\
\hline
\end{tabular}

Finally, with emission factors expressed in $\mathrm{g} / \mathrm{kWh}$, the amount of emissions of pollutant $p$ per link can be calculated according with:

$$
E_{i j k, p}[g]=E F_{p} \times P_{D} \times \frac{\text { LDist }_{i j k}}{\text { Lspeed }_{i j k}}
$$




\subsubsection{Rail Transport Emissions}

For rail transport, the propulsion units considered are line-haul locomotives, which are used for long-distance freight rail traction. These are equipped with diesel engines with a power output usually between 400 and $4000 \mathrm{~kW}$, with those used for freight trains being at the upper end of this range.

For estimating rail transport emissions, the methodology suggested in the European Environment Agency Emission Inventory Guidebook [38] is used: first, the fuel consumption is estimated, and then, the emission factors for line-haul locomotives are used. The use of conventional fuel oil, similar to the one used in road transport, is considered, this having a sulfur content of $0.001 \%$ by mass $(10 \mathrm{ppm})$ according with the EURO V standard. The fuel consumption for line-haul locomotives can be estimated using the fuel consumption factor $\operatorname{TraFC}_{i j}$ of $219 \mathrm{~kg}$ fuel $/ \mathrm{h}$. Then, using the emission factors $E F_{\text {train, }}$ in $\mathrm{kg} /$ tonne, the amount of emissions of pollutant $p$ in g per link can be calculated as follows:

$$
E_{i j k, p}[g]=E F_{\text {train }, p} \times \operatorname{TraFC}_{i j} \times \frac{\text { LDist }_{i j k}}{\text { LSpeed }_{i j k}}
$$

Emissions per trailer are computed by dividing total emissions per link or path by the train's freight capacity in number of trailers $\operatorname{TraCap}_{i j}$ and its capacity utilization factor TraUt $t_{i j}$.

For $\mathrm{SO}_{2}$, the emission factor can be calculated according with Equation (9) and is therefore equal to $0.02 \mathrm{~kg}$ /tonne. To calculate the emission factors in $\mathrm{CO}_{2}$-eq, the global warming potential of each main $\mathrm{GHG}\left(\mathrm{CO}_{2}, \mathrm{CH}_{4}\right.$, and $\left.\mathrm{N}_{2} \mathrm{O}\right)$ is multiplied by the emission factors $E F_{\text {train, }, p}$ in $\mathrm{kg} /$ tonne also available in the guidebook. For diesel, the $\mathrm{CO}_{2}$-eq emission factor is $3.181 \mathrm{~g} / \mathrm{g}$, and it is $3.104 \mathrm{~g} / \mathrm{g}$ for LNG. The indirect emissions for electric locomotives are coming from the production of electricity, but those are not considered in this model.

Emissions abatement technologies such as EGR and SCR for $\mathrm{NO}_{x}$ and DPF for PM are becoming available for diesel railway engines [38]. Using a designated variable in the model, the user can state if the train is reducing emissions using DPF + EGR/SCR or not. When a locomotive is equipped with a DPF, a lower value for PM emissions of $0.012 \mathrm{~g} \mathrm{PM} / \mathrm{kg}$ fuel is used. For railways, 95\% of calculated $\mathrm{PM}_{10}$ is $\mathrm{PM}_{2.5}$ [37]. Emission factors and reductions for when abatement technologies are used are the ones in Table 7.

Table 7. Emission factors and emission abatement technologies for rail.

\begin{tabular}{cccc}
\hline & & Fuel Type + Technology & \\
& Diesel & +DPF & +EGR/SCR \\
\hline $\mathrm{NO}_{\mathrm{x}}[\mathrm{kg} /$ tonne $]$ & 63 & - & $-50 \%$ \\
$\mathrm{PM}_{10}[\mathrm{~kg} /$ tonne $]$ & 1.2 & $-99 \%$ & - \\
$\mathrm{PM}_{2.5}[\mathrm{~kg} /$ tonne $]$ & 1.1 & $-99 \%$ & - \\
$\mathrm{CO} 2[\mathrm{~kg} /$ tonne $]$ & 3140 & - & - \\
$\mathrm{SO}_{2}[\mathrm{~kg} /$ tonne $](10 \mathrm{ppm})$ & 0.02 & - & - \\
\hline
\end{tabular}

\subsection{Numerical Implementation}

As mentioned, the methodology described above is implemented in a numerical tool, along with another method for estimating the external costs of transport. This numerical tool (SA, Sustainability Analyst) was built for research purposes only. SA runs through an executable file and is coded in Fortran. The software is controlled with a Log File that contains the paths for the input and output data, as synthesized below in Figure 1. 
Input Data files (.txt)

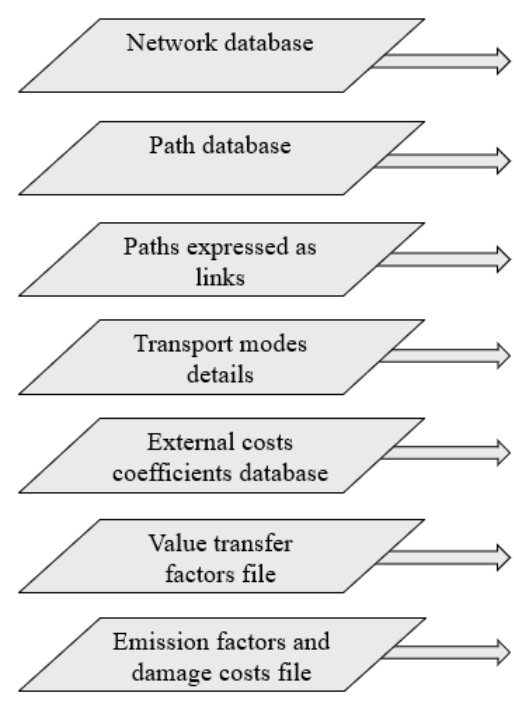

\section{Output Data files (.txt)}

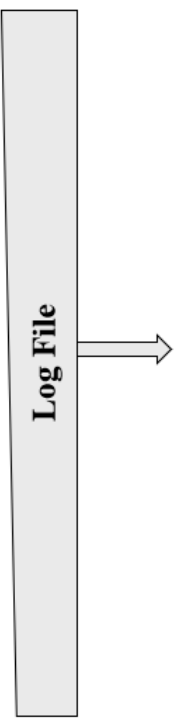

External costs and emissions results per path

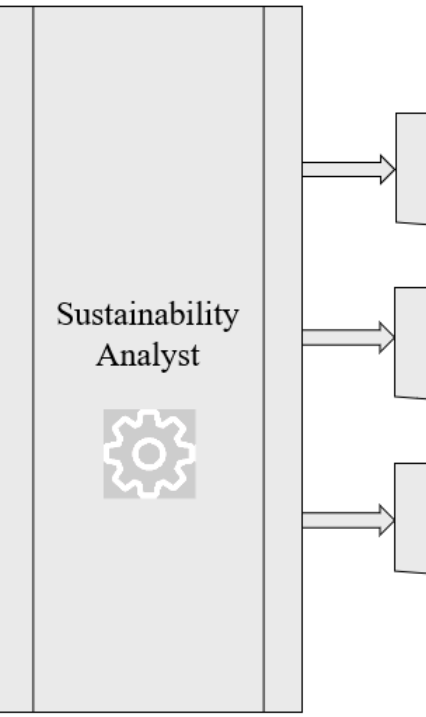

External costs and emissions results per path list formatted

External costs and emissions results per country

Figure 1. Data flowchart of the software Sustainability Analyst.

\section{Numerical Results}

\subsection{Case Study Specification}

The numerical model for calculating transport emissions presented in the previous section will now be illustrated using a case study for a route between Portugal and Germany, using different alternative intermodal transport chains (which include short sea shipping). Furthermore, two different emissions scenarios are chosen for these transport chains between Portugal and northwestern Europe. The Iberian Peninsula has significant volumes of trade with central European countries; therefore, this corridor is a suitable candidate for achieving substantial modal shifts from road to sea [41]. Concerning the geographical regions in the study, it is also worth pointing out that the English Channel and North Sea form an ECA and, therefore, have stricter emissions control standards both for $\mathrm{SO}_{\mathrm{x}}$ and $\mathrm{NO}_{\mathrm{x}}$.

This case study will present numerical results for emissions arising from different alternative transport chains involving all transport modes and will compare these results. The origin and destination are kept fixed for all chains and correspond to the cities of Porto and Stuttgart, which are chosen as both are significant manufacturing centers. The characteristics of the transport chains are presented in Table 8 and the routes used by the different transport modes are shown in Figure 2. It is important to note that the ship sails at a moderate speed of 15 knots, which is well below the ship's design speed of 20 knots and that we assumed a time in port of $6 \mathrm{~h}$ in both the departure and destination ports, when applicable.

In addition to the transport chains detailed above, two emission scenarios were chosen according with the current available technologies and regulatory frameworks. These scenarios were chosen so that they represent a realistic scenario (for the year of 2021) and an optimistic scenario (with significant uptake of LNG by the transport industry), and they have been used to calculate emissions using the numerical model. The vehicles' fuel and emission control characteristics selected are detailed below in Table 9, and the emission factors selected in the calculations may be found in Table S2 (Supplementary Materials). 
Table 8. General characteristics of different transport chains (A: unimodal; B-E: intermodal) between Porto and Stuttgart.

\begin{tabular}{|c|c|c|c|c|}
\hline Transport Chain & Name & Description & Distances & Average Speed \\
\hline A & Road direct & Long range road haulage & Road distance: $2262.6 \mathrm{~km}$ & Road: $80 \mathrm{~km} / \mathrm{h}$ \\
\hline B & Intermodal—road and SSS & $\begin{array}{l}\text { Ro-Ro cargo ship } \\
\text { Leixões-Rotterdam + Medium } \\
\text { range road haulage }\end{array}$ & $\begin{array}{l}\text { Road distance: } 640.3 \mathrm{~km} \\
\text { Sea distance: } 1720 \mathrm{~km}\end{array}$ & $\begin{array}{l}\text { Road: } 80 \mathrm{~km} / \mathrm{h} \\
\text { Sea: } 15 \mathrm{kn}\end{array}$ \\
\hline C & $\begin{array}{l}\text { Intermodal-road, SSS } \\
\text { and IWW }\end{array}$ & $\begin{array}{l}\text { Ro-Ro cargo ship } \\
\text { Leixões-Rotterdam + Inland } \\
\text { vessel Rotterdam-Duisburg + } \\
\text { Medium range road haulage }\end{array}$ & $\begin{array}{l}\text { Road distance: } 450.2 \mathrm{~km} \\
\text { Sea distance: } 1720 \mathrm{~km} \\
\text { Inland distance: } 234.6 \mathrm{~km}\end{array}$ & $\begin{array}{l}\text { Road: } 80 \mathrm{~km} / \mathrm{h} \\
\text { Sea: } 15 \mathrm{kn} \\
\text { Inland: } 10 \mathrm{kn}\end{array}$ \\
\hline D & Intermodal—road and rail & $\begin{array}{c}\text { Long-haul freight train } \\
\text { Cacia-Mannheim + Short range } \\
\text { road haulage }\end{array}$ & $\begin{array}{l}\text { Road distance: } 224.5 \mathrm{~km} \\
\text { Rail distance: } 2216.8 \mathrm{~km}\end{array}$ & $\begin{array}{l}\text { Road: } 80 \mathrm{~km} / \mathrm{h} \\
\text { Rail: } 37 \mathrm{~km} / \mathrm{h}\end{array}$ \\
\hline E & $\begin{array}{l}\text { Intermodal—road, SSS } \\
\text { and rail }\end{array}$ & $\begin{array}{l}\text { Ro-Ro cargo ship } \\
\text { Leixões-Rotterdam + Long-haul } \\
\text { freight train Rotterdam-Mannheim } \\
+ \text { Short range road haulage }\end{array}$ & $\begin{array}{l}\text { Road distance: } 148.4 \mathrm{~km} \\
\text { Sea distance: } 1720 \mathrm{~km} \\
\text { Rail distance: } 548.18 \mathrm{~km}\end{array}$ & $\begin{array}{l}\text { Road: } 80 \mathrm{~km} / \mathrm{h} \\
\text { Sea: } 15 \mathrm{kn} \\
\text { Rail: } 37 \mathrm{~km} / \mathrm{h}\end{array}$ \\
\hline
\end{tabular}

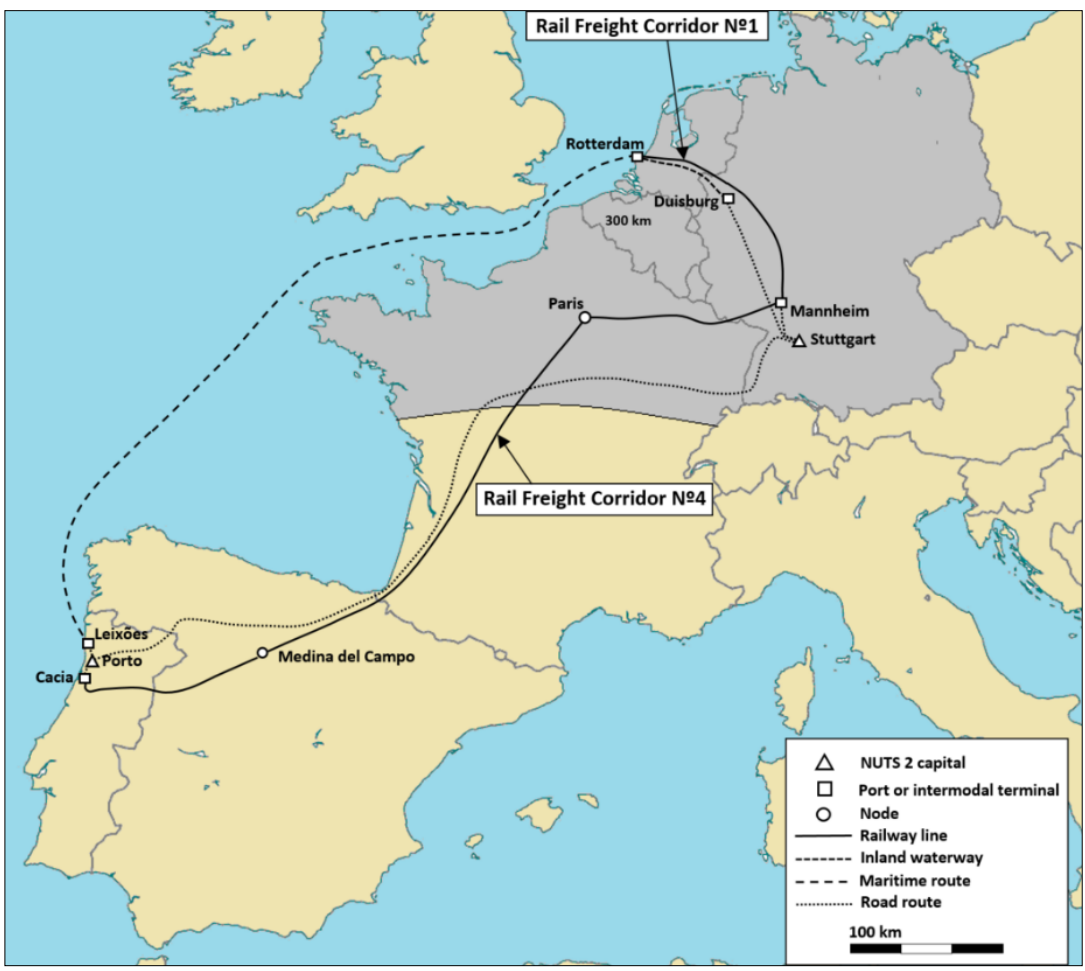

Figure 2. Road, rail, IWW, and maritime routes used in transport chains between Porto and Stuttgart.

Table 9. Vehicles' power and fuel and emissions control characteristics in representative emission scenarios.

\begin{tabular}{|c|c|c|c|}
\hline \multicolumn{2}{|r|}{ Scenario 1: High Emissions } & \multicolumn{2}{|r|}{ Scenario 2: Low Emissions } \\
\hline 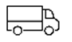 & Truck diesel fueled EURO IV & $a=0$ & Truck LNG fueled EURO VI \\
\hline$\dddot{m}$ & Diesel train Stage III compliant engine & 茯 & $\begin{array}{c}\text { Diesel train Stage III compliant engine } \\
\text { with DPF + SCR/EGR }\end{array}$ \\
\hline 器 & $\begin{array}{l}\text { Inland vessel with CCNR-2 compliant } \\
\text { engine using diesel with DPF and } \\
\text { SCR installed }\end{array}$ & 器 & $\begin{array}{c}\text { Inland vessel with Stage V compliant } \\
\text { engine using LNG }\end{array}$ \\
\hline 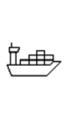 & $\begin{array}{l}\text { Ro-Ro cargo ship using VLSFO }(0.5 \% \text { S) } \\
\text { with Tier II compliant engine and WS + } \\
\text { EGR only inside ECAs }\end{array}$ & 息 & $\begin{array}{l}\text { Ro-Ro cargo ship using LNG with Tier } \\
\text { III compliant engine at all times }\end{array}$ \\
\hline
\end{tabular}


Table 10 shows the technical characteristics of the vehicles, which are kept constant between emission scenarios, namely details on design, cargo capacity, main dimensions, installed power (propulsion and auxiliary), and utilization factor.

Table 10. Detailed technical characteristics of vehicles used in transport chains.

\begin{tabular}{|c|c|c|c|}
\hline Truck & Train & Inland Vessel & SSS Vessel \\
\hline $\begin{array}{c}\text { Engine power: } 365 \mathrm{~kW} \\
\text { Engine-specific fuel } \\
\text { consumption: } 227 \mathrm{~g} / \mathrm{kWh} \\
\text { Gross weight: } 40 \mathrm{t} \\
\text { Cargo utilization factor: } 1.0\end{array}$ & $\begin{array}{l}\text { Engine fuel consumption: } 219 \\
\text { kg fuel/h } \\
\text { Cargo capacity: } 40 \text { FEUs } \\
\text { Cargo utilization factor: } 1.0\end{array}$ & $\begin{array}{c}\text { Medium-speed diesel main } \\
\text { engine } \\
\text { Power: } 737 \mathrm{~kW} \\
\text { Design speed } 10 \mathrm{kn} \\
\text { Cargo capacity: } 50 \text { FEUsCargo } \\
\text { utilization factor: } 1.0\end{array}$ & $\begin{array}{c}\text { Ro-Ro cargo ship } \\
\text { Lbp: } 180 \mathrm{~m}, \mathrm{~B}: 27 \mathrm{~m}, \mathrm{~T}: 7.5 \mathrm{~m} \\
\text { Medium-speed diesel main } \\
\text { engine Power: } 12,000 \mathrm{~kW} \\
\text { Auxiliary engines total power: } \\
1270 \mathrm{~kW} \\
\text { Design speed } 20 \mathrm{kn} \\
\text { Average time spent in port } 6 \mathrm{~h} \\
\text { Cargo capacity: } 239 \text { trailers } \\
\text { Cargo utilization factor: } 1.0\end{array}$ \\
\hline
\end{tabular}

\subsection{Comparison with Results from MAE Calculator}

The results of the numerical model detailed in Section 3 and implemented in SA will first be compared with those of the MAE External Cost Calculator (MAE), which was developed in the context of the MED ATLANTIC ECOBONUS (MAE) ${ }^{1}$ project. This calculator is available online and allows for the comparison of unit external costs and emissions between unimodal road only alternatives and intermodal alternatives for freight cargo on ro-ro vessels through the motorways of the sea. The calculator considers as a unit of cargo an HGV or trailer and takes the total distances traveled by road and at sea, the average ship speed, fuel type, and emissions reduction technologies as entry data.

The comparison of the overall emission results for multimodal transport chain B in scenario 1 between MAE and SA is presented in Table 11. Emissions in port were not compared. For the road links, the small difference in fuel consumption arises from the different method used to estimate it. MAE uses a constant reference fuel consumption of $36 \mathrm{~L} / 100 \mathrm{~km}$, whereas in SA, each link has a fuel consumption rate dependent on the speed and specific fuel consumption of the engine. That explains the difference in $\mathrm{CO}_{2}$-eq emissions that are proportional to fuel consumption. That difference is compensated in $\mathrm{SO}_{2}$ emissions by the $7 \%$ higher emission factor used by MAE. This might be because SA only considers $\mathrm{SO}_{2}$ emissions arising from the combustion process, but there are other substances containing sulfur being released in the combustion process that should the emission factor. For $\mathrm{NO}_{\mathrm{x}}$ and $\mathrm{PM}$ emissions, MAE includes a critical review and correction of $158 \%$ and $210 \%$, respectively, to the standards' emission factors based on real-world data that explains the recorded differences.

Table 11. Comparison of results with MAE calculator-SSS-based route B.

\begin{tabular}{|c|c|c|c|c|c|c|}
\hline & Mode & Fuel Consumption & $\mathrm{CO}_{2}-\mathrm{Eq}(\mathrm{kg})$ & $\mathrm{NO}_{x}(\mathrm{~g})$ & $\mathrm{PM}_{2.5}(\mathrm{~g})$ & $\mathrm{SO}_{2}(\mathrm{~g})$ \\
\hline \multirow{2}{*}{ MAE } & Road & $192.9 \mathrm{Kg}$ & 613.2 & 2851.2 & 21.7 & 4.0 \\
\hline & SSS & 33 tons/day & 1120.5 & $12,043.6$ & 543.1 & 2292.2 \\
\hline \multirow{2}{*}{ SA } & Road & $201.2 \mathrm{Kg}$ & 640.0 & 3102.6 & 17.7 & 3.9 \\
\hline & SSS & 30 tons/day & 1092.8 & $13,603.3$ & 1065.7 & 1981.1 \\
\hline \multirow{2}{*}{ Difference } & Road & $-4 \%$ & $-4 \%$ & $-8 \%$ & $22 \%$ & $3 \%$ \\
\hline & SSS & $9 \%$ & $3 \%$ & $-11 \%$ & $-49 \%$ & $16 \%$ \\
\hline
\end{tabular}

Regarding maritime transport emissions, there is less than $10 \%$ difference in fuel consumption estimation, and the most significant emission deviation is for PM. In fact, MAE is using an emission factor that is not updated according with the most recent inventories and that does not correspond to the entered fuel of $0.5 \%$ sulfur content as per 
the references. Therefore, a much lower emission factor is used as reference explaining the difference in the results. In addition, the base specific fuel consumption behind the $\mathrm{g} / \mathrm{g}$ emission factors in the calculator is higher than the one used in SA. The vessel fuel consumption is computed for the average ferry/ro-ro vessel as a function of the speed not taking into account the specific characteristics of main and auxiliary engines and draught.

\subsection{Detailed Numerical Results}

Figure 3 shows the air pollutant and $\mathrm{CO}_{2}$-eq emissions for the various transport chains in both scenarios in quantities per trailer. As expected, in both scenarios, transport chain A (unimodal) produces the highest values per unit of cargo of $\mathrm{CO}_{2}$-eq emissions. In scenario $1, \mathrm{CO}_{2}$-eq emissions can drop more than $55 \%$ when intermodal transport chains are chosen. In scenario 2, the fuel switch from conventional fuels to LNG, in all modes but rail, is reflected with just a slight decrease in $\mathrm{CO}_{2}$-eq emissions-see Table 12. Although the carbon content of this fuel is lower, other exhaust gases, such as methane, with very high global warming potential are emitted at higher rates in gas burning engines than when conventional fuels are used. As stated in other studies [12], LNG has clear advantages in reducing air pollutants and thus its local impact, but by itself, it is not a clear path toward the achievement of the GHG emissions reduction targets.

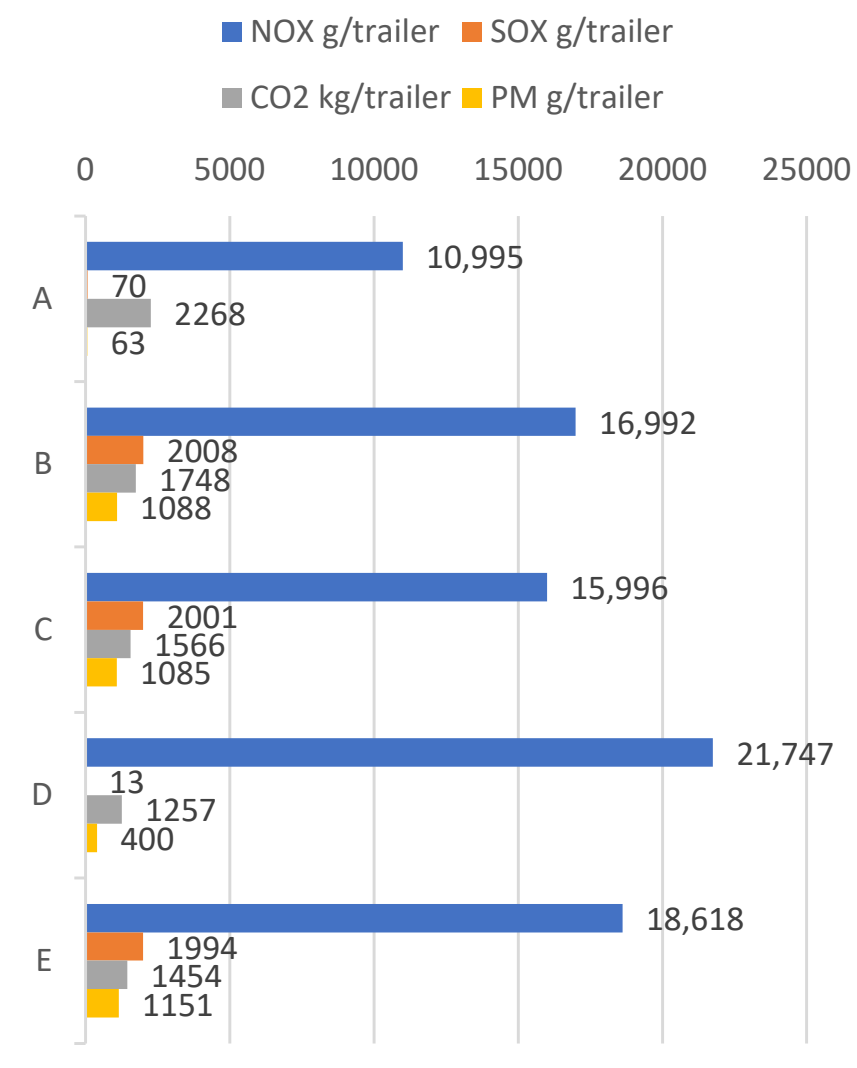

(a)

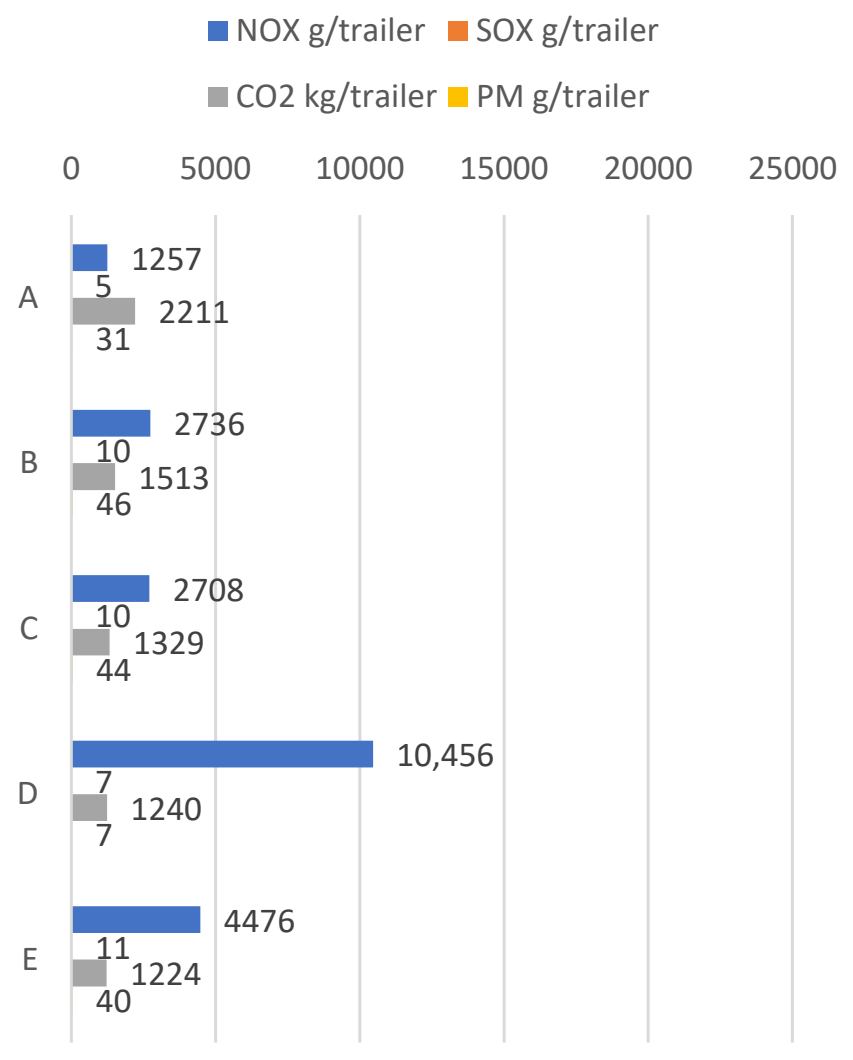

(b)

Figure 3. Emissions per trailer: (a) scenario 1; (b) scenario 2. 
Table 12. Emissions reduction between scenarios 1 and 2 .

\begin{tabular}{ccccc}
\hline & $\mathbf{N O}_{\mathbf{x}}$ & $\mathbf{S O}_{\mathbf{2}}$ & $\mathbf{C O}_{\mathbf{2}} \mathbf{- E q}$ & $\mathbf{P M}$ \\
\hline $\mathbf{A}$ & $-89 \%$ & $-93 \%$ & $-3 \%$ & $-50 \%$ \\
$\mathbf{B}$ & $-84 \%$ & $-99 \%$ & $-13 \%$ & $-96 \%$ \\
$\mathbf{C}$ & $-83 \%$ & $-99 \%$ & $-15 \%$ & $-96 \%$ \\
$\mathbf{D}$ & $-52 \%$ & $-48 \%$ & $-1 \%$ & $-98 \%$ \\
$\mathbf{E}$ & $-76 \%$ & $-99 \%$ & $-16 \%$ & $-97 \%$ \\
\hline
\end{tabular}

Regarding air pollutants, in scenario 1, the higher sulfur content of the marine fuel considered and the more permissible $\mathrm{NO}_{\mathrm{x}}$ limits of Tier II for ships and Stage III for trains, when compared to EURO V for trucks, explain the higher quantity of $\mathrm{NO}_{\mathrm{x}}$ and $\mathrm{SO}_{2}$ emissions of the intermodal transport chains $\mathrm{B}$ to $\mathrm{E}$. The higher sulfur content of marine fuels explains the greater emissions in SSS-based intermodal transport chains B, C, and $\mathrm{E}$, where the largest distance is traveled by sea. $\mathrm{NO}_{\mathrm{x}}$ emissions in the diesel-based rail intermodal transport chain $\mathrm{D}$ reflect the lower emission standards that still apply to that mode when compared with the other inland modes. In scenario 2, it may be seen that $\mathrm{SO}_{2}$ and $\mathrm{PM}$ emissions almost disappear, and $\mathrm{NO}_{\mathrm{x}}$ emissions are cut to more than $1 / 5$, except in transport chain $\mathrm{D}$, also because of the lower standards for a diesel train. The general conclusion is that transport chains based on SSS are preferable in terms of $\mathrm{CO}_{2}$, either in scenario 1 or scenario 2, but in terms of $\mathrm{NO}_{\mathrm{x}}, \mathrm{SO}_{2}$, and $\mathrm{PM}$, the situation in scenario 1 for SSS is not positive. In scenario 2, the disadvantage of SSS is solved for $\mathrm{SO}_{2}$ and $\mathrm{PM}$ but remains significant as regards $\mathrm{NO}_{x}$.

Figure 4 shows, for each intermodal chain based on emissions scenarios 1 and 2, respectively, the share of each mode in total $\mathrm{CO}_{2}$-eq emissions per trailer. While the amount of emissions is also proportional to the distance traveled, there is a clear imbalance between modes within each transport chain. For example, in the SSS-based transport chain B, where $73 \%$ of the traveled distance is by sea, that leg is responsible for $63 \%$ of overall $\mathrm{CO}_{2}$-eq emissions of the trip due to the higher footprint of the road leg. The same happens in the rail-based transport chain $\mathrm{D}$ with $9 \%$ of distance traveled by road being responsible for almost $20 \%$ of overall $\mathrm{CO}_{2}$-eq emissions per trailer. In the lower emissions scenario 2 , the proportion between distance traveled by road and emissions share slightly increases with trucks and vessels using the same type of fuel. This is because the EGR used in scenario 1 has an effect in $\mathrm{CO}_{2}$-eq emissions that is not present in scenario 2, making the drop in the emission factor between scenarios 1 and 2 in the case of the ship larger than in the case of the truck.

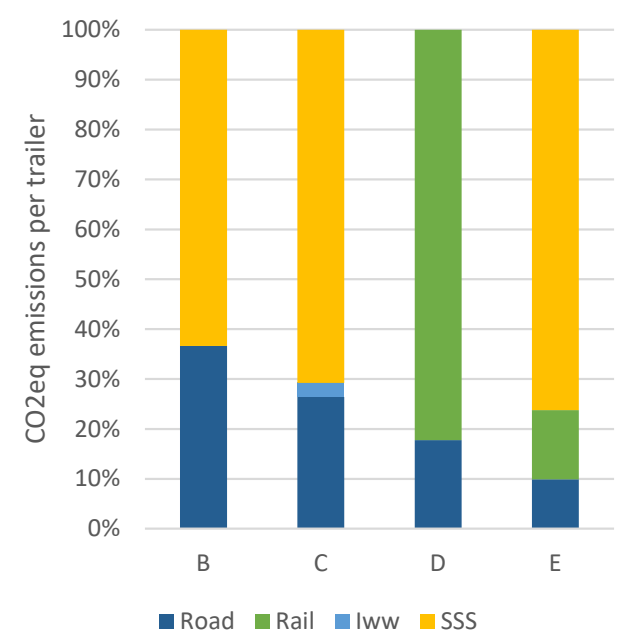

(a)

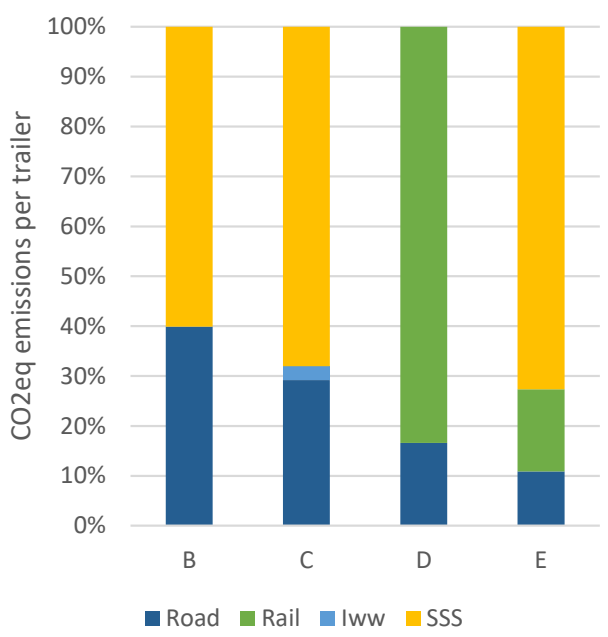

(b)

Figure 4. Share of $\mathrm{CO}_{2}$-eq emissions per transport mode: (a) scenario 1; (b) scenario 2. 
On the other hand, Figure 5 shows, for each transport chain and emissions scenario, respectively, the share of each mode in total $\mathrm{NO}_{x}, \mathrm{SO}_{2}$, and $\mathrm{PM}$ emissions. In transport chains $B$ and $C$, while the sea leg is around $70 \%$ of the distance traveled, more than $80 \%$ of air pollutants arise in that leg of which only around $1-2 \%$ are calculated to be emissions in port. Looking at the total emissions associated with shipping (sea+maneuvering+port), the sea leg presents the highest value of emissions per $\mathrm{km}$ when compared with the other modes in those transport chains. Similarly, the higher value of emissions per $\mathrm{km}$ in the rail leg is highlighted in transport chains $\mathrm{D}$ and $\mathrm{E}$. This is particularly evident in transport chain E (scenario 2) with the train being the only mode not using LNG. It is also clear that in terms of air pollutants, the relative competitiveness of SSS does not improve significantly in scenario 2 compared to scenario 1.

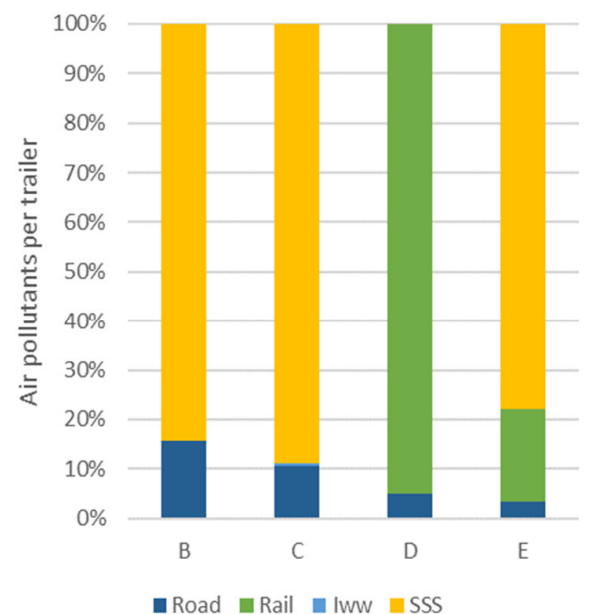

(a)

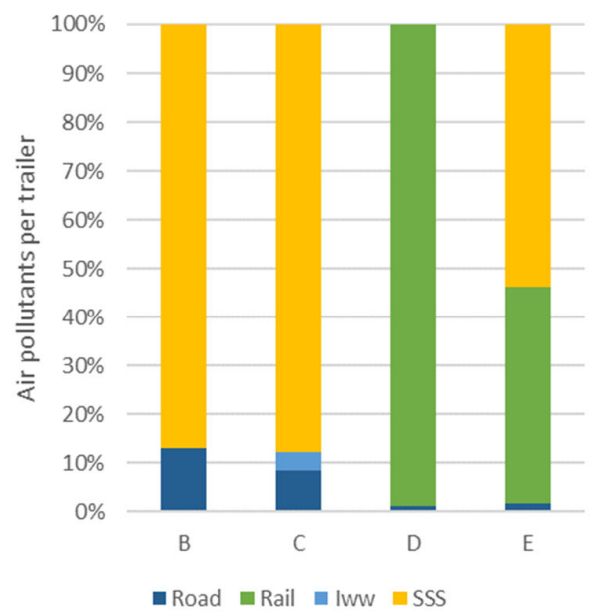

(b)

Figure 5. Share of $\mathrm{NO}_{\mathrm{x}}, \mathrm{SO}_{2}$, and PM emissions per transport mode: (a) scenario 1; (b) scenario 2.

The results of this numerical model may also be extracted per country, as that is an attribute of each link in the network model. Figure 6 shows that most pollutants are emitted in the countries of transit, where the distance traveled is larger, affecting less the origin and destination countries. This shows the spread of the negative effects of transport decisions beyond the trading partners involved-the external effects-and the potential for its reduction within each country. In scenario 2, the relative competitiveness of the SSS-based transport chains is significantly reduced just in terms of quantity of emissions. One might think that shifting the traffic to the sea, where no people, buildings, or crops are exposed to the negative effects of air pollutants is by itself positive, especially in this corridor with a significant part of the sea leg located far from land around the Gulf of Biscay. However, the impact of emissions in port and around densely populated coastal areas cannot be neglected. Moreover, it is important to note that a higher quantity of emissions in a certain region is not proportional to higher damage. The dimension of risk assessment associated with emission quantities is left out in this study.

The numerical model not only allows for the study of a set of alternative transport chains between a pair O/D, but at the same time, for several combinations of O/D (representing NUTS2 regions). An example of the results obtained when multiple pairs of $\mathrm{O} / \mathrm{D}$ are studied at the same time (regional study) is given in Figure 7, with the previously used destination of Stuttgart (capital of region DE11) highlighted. In these maps, the same combination of modes in each transport chain is used. They show, for both emission scenarios, the ratio between total $\mathrm{CO}_{2}$-eq emissions for unimodal transport chain $\mathrm{A}$ and those for the intermodal SSS transport chain B. The largest difference is recorded for the regions around the port of Rotterdam, where choosing road instead of the closely available sea connection becomes costlier in terms of total $\mathrm{CO}_{2}$-eq emissions. However, the regions further away from the port and closer to the origin by road are attracted by unimodal 
solution A because of the shorter traveled distances by road. When both transport modes involved (trucks and Ro-Ro) are using the same fuel, as it is the case in scenario 2, the choice of the road solution rather than the intermodal SSS-based solution becomes even less competitive in terms of reducing global GHG emissions, doubling the quantity of emissions for most of the destinations studied.

\section{NOx, SO2 and PM emissions in $\mathrm{g} /$ trailer}

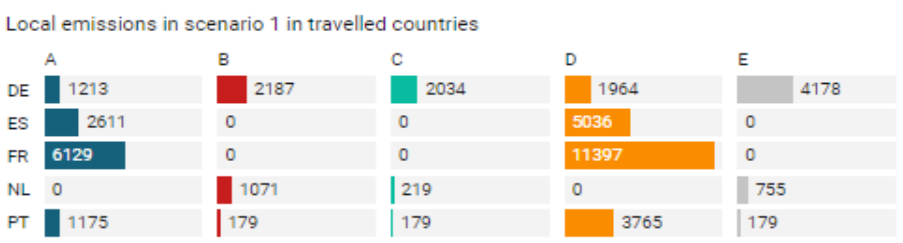

(a)

NOx, SO2 and PM emissions in $\mathrm{g} /$ trailer

\begin{tabular}{|c|c|c|c|c|}
\hline A & B & c & D & E \\
\hline DE $\mid 141$ & 254 & 266 & 711 & 1798 \\
\hline ES 303 & 0 & 0 & 2472 & 0 \\
\hline FR 712 & 0 & 0 & 5596 & 0 \\
\hline NL $\quad 0$ & | 124 & 82 & 0 & 315 \\
\hline PT | 137 & 20 & 20 & 1692 & 20 \\
\hline
\end{tabular}

(b)

Figure 6. Emissions per country: (a) scenario 1; (b) scenario 2.

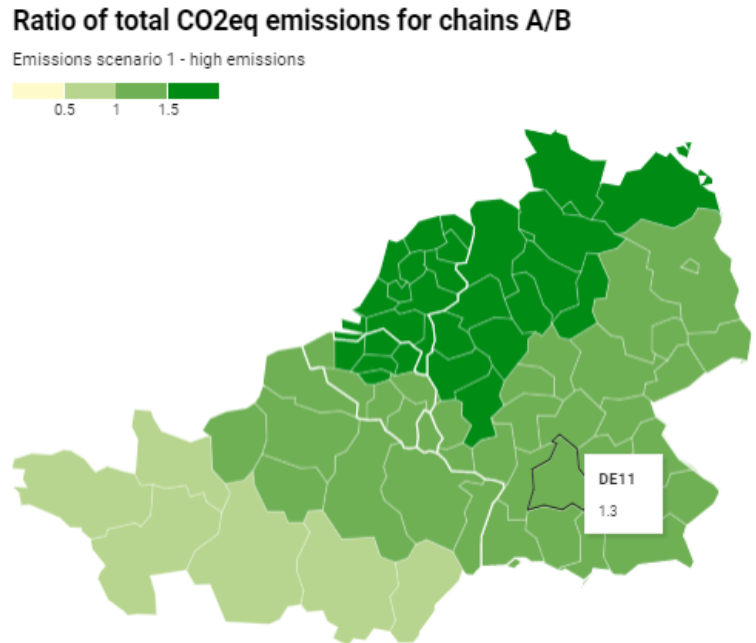

(a)
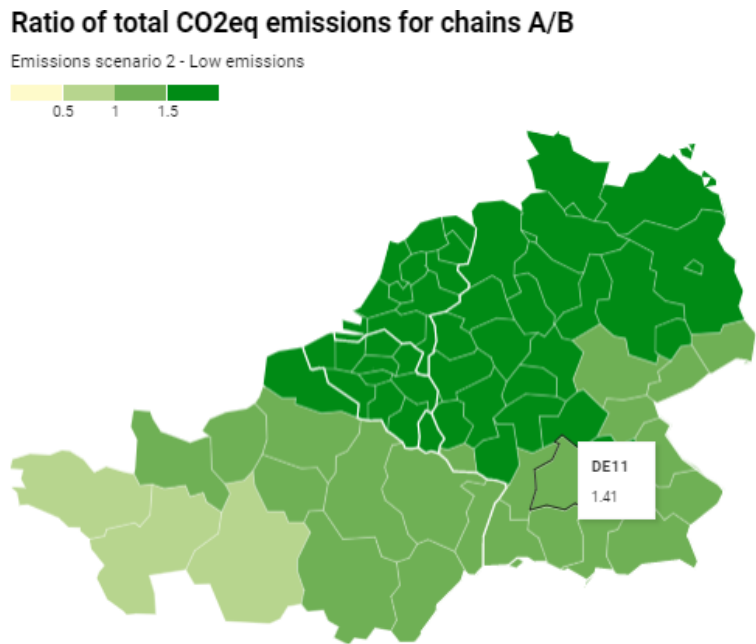

(b)

Figure 7. Ratio of $\mathrm{CO}_{2}$-eq between unimodal chain A and intermodal SSS-based chain B: (a) scenario 1 ; (b) scenario 2 (created with Datawrapper).

Figure 8 shows the ratio of $\mathrm{CO}_{2}$-eq and air pollutant emissions, in $\mathrm{kg}$ and $\mathrm{g}$ per trailer, respectively, per distance traveled, in $\mathrm{km}$, by each transport mode. The ratio is the average obtained using the same vehicle type in all alternative transport chains between all 75 origin/destination combinations used in the regional study before. This is representative of the rates of pollution between modes, using the vehicle types described in Tables 9 and 10, in this transport corridor. As proved before, road freight transport is, in this corridor, the most pollutant alternative in terms of GHG emissions per trailer per distance traveled in both emission scenarios. On average, between Porto and the 75 destinations in the same region studied before, a ratio of two times the distance traveled by road can be traveled by sea causing the same amount of GHG emissions. On the other hand, in both scenarios, more than three times the distance traveled by sea can be traveled by road causing the 
same amount of combined $\mathrm{NO}_{x}, \mathrm{SO}_{2}$, and $\mathrm{PM}$ emissions. Given that a diesel train is always considered, in scenario 2, the ratio of air pollutants per $\mathrm{km}$ from rail is the highest.

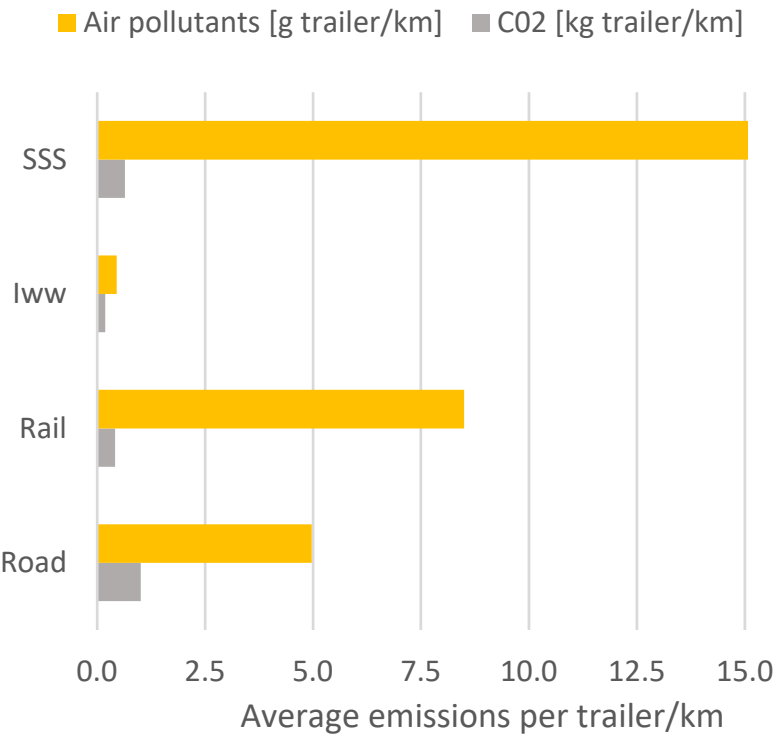

(a)
\# Air pollutants [g trailer $/ \mathrm{km}] \quad$ c02 [kg trailer $/ \mathrm{km}]$

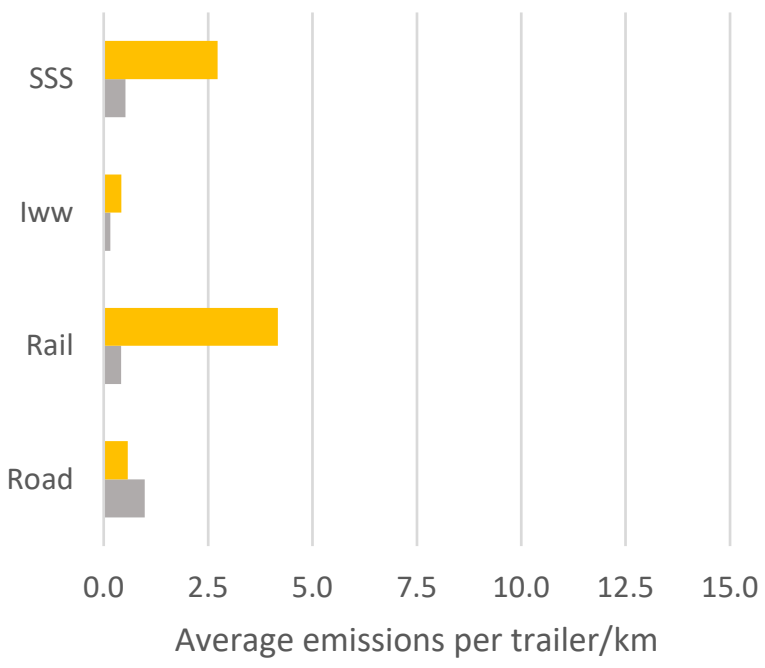

(b)

Figure 8. Average emissions per trailer per distance traveled in each mode in the corridor: (a) scenario 1; (b) scenario 2.

It is also possible to identify the preferable transport chain for each NUTS2 destination (keeping the origin constant) based on total $\mathrm{CO}_{2}$-eq emissions as shown in Figure 9 for both emission scenarios. In the two scenarios, SSS-based transport chains B and C are preferred in most coastal regions in terms of lowering global GHG emissions in this corridor. The attractiveness of SSS-based transport chains further increases in the lower emissions scenario 2 when the same fuel type (LNG) is used by all modes expect rail. The unimodal transport chain A is attractive for coastal regions located further away from the port of Rotterdam, for which the road leg increases to the point that its emissions surpass the large emissions arising in the road direct chain A. Under scenario 1, the rail direct transport chain $\mathrm{D}$ is very competitive in the inland regions, while in scenario 2 , transport chain $\mathrm{D}$ is substituted by E (SSS plus train from Rotterdam to Mannheim). Although the results show that in scenario 1 , a rail direct transport chain from Portugal, virtually represented by transport chain $\mathrm{D}$, can be competitive in terms of $\mathrm{CO}_{2}$-eq emissions in this corridor for some NUTS 2 regions, the lack of railway infrastructure and the discrepancy between technical specifications in the Iberian Peninsula and in other EU countries (track gauge, lack of electrification, and even maximum train length allowed) make transport chain $\mathrm{D}$ not yet a realistic scenario. Nevertheless, it is also possible to consider an electric train in the model. When an interoperable and total electrified freight railway-zero carbon network - exists between the origin and destination countries in study, route alternative $\mathrm{D}$ with the majority of the distance traveled by train becomes the most attractive for the regions in the study, except for the closest area to the port of Rotterdam, even though it is not considering the indirect emissions from the production of electricity. 


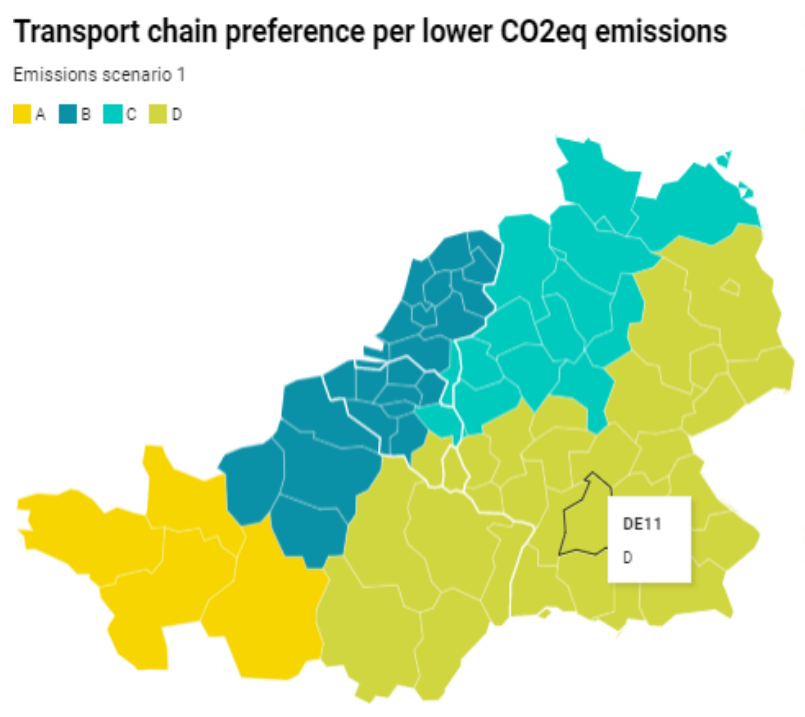

(a)

\section{Transport chain preference per lower C02eq emissions}
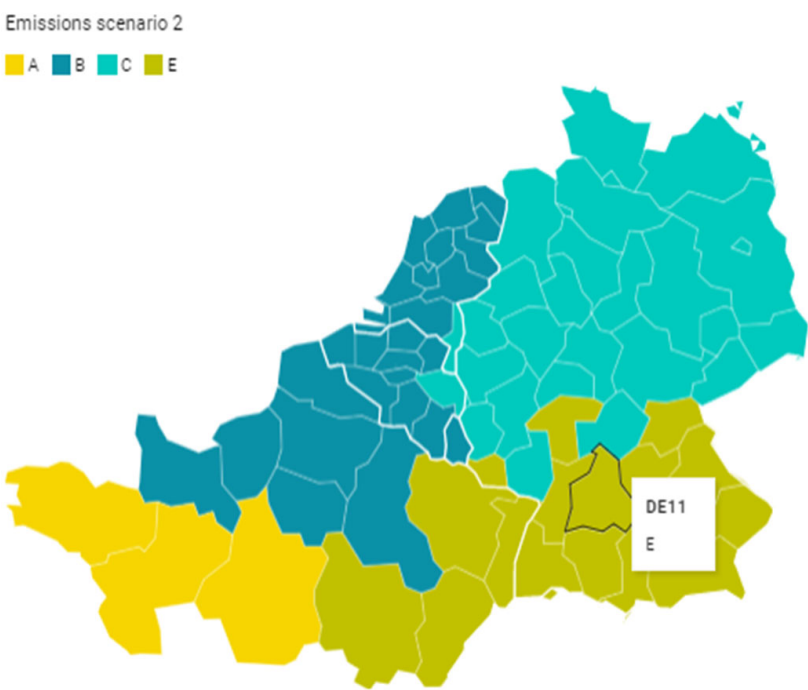

(b)

Figure 9. Transport chain preference per lower $\mathrm{CO}_{2}$-eq emissions: (a) scenario 1; (b) scenario 2 (created with Datawrapper).

\section{Conclusions}

This paper has presented a numerical model for estimating emissions arising in intermodal transport chains using a detailed database of transport networks, including road, rail, inland, and sea components. This model is based on an extensive literature review on fuel consumption and emission factors estimation techniques, emission standards and abatement technologies for all transport modes at an individual level. A numerical tool has been developed that is based on this model, allowing a broad spectrum of numerical results aimed at promoting the integration of maritime transportation in intermodal transport chains, the promotion of environmentally friendly transport chains, and adequate transport policies. These results also explore the consequences of regulatory and technological developments in the transport sector.

A case study dedicated to intermodal transport chains in the Atlantic Corridor has been carried out to illustrate the broad results that can be obtained using this numerical tool. Two different emission scenarios were chosen for a set of unimodal and intermodal routes (SSS and rail based) between Portugal and northwestern Europe. $\mathrm{CO}_{2}$-equivalent, $\mathrm{NO}_{\mathrm{x}}, \mathrm{SO}_{2}$, and $\mathrm{PM}$ emissions results were presented in quantities per trailer for each route along with the share of emissions per transport mode, in the case of intermodal routes, and the quantities per country.

The results for road and maritime emissions were first compared with the values obtained using the MED Atlantic Ecobonus project calculator. For road transport, a maximum difference of $18 \%$ between PM emission results was obtained. This is found to be due to rounding differences in the emission factors used, the fact that the calculator includes a critical review and correction to the standard emission factors based on real-world data, and an $8 \%$ deviation in fuel consumption because the calculator uses constant fuel consumption values along the distance traveled. Regarding maritime transport emissions, there is a $9 \%$ difference in fuel consumption estimation, and the largest emission deviation is in PM, for which the emission factor is not updated in accordance with the most recent inventories. This comparison has shown us once again that there are no benchmark values for emissions and fuel consumption and that theoretical values may be far from a reality that is changing fast. Emission factors and the engine performance must be considered according with the most recent inventories.

The case study results include the emissions of pollutants with larger local impact, which are presented per country crossed by the transport chains. Most pollutants are 
emitted in the countries of transit where the distance traveled is higher, thus showing the impact of less sustainable transport decisions (use of road haulage) in society. When using short sea shipping, a significant part of the sea legs is located far from land (Gulf of Biscay) and one might think that shifting the traffic to sea, where there is no exposure, is positive. However, a detailed damage assessment may conclude otherwise when looking at the total impact of transport chains that include road legs and emissions at port in heavily populated regions around the ports of Leixões and Rotterdam. The average pollution rate (in quantities per $\mathrm{km}$ ) of each transport mode in this corridor was also assessed using results from a regional study connecting the same origin to 75 different NUTS 2 in Northern Europe. On average, in this corridor, two times the distance traveled by road can be traveled by sea causing the same amount of GHG emissions. On the other hand, more than three times the distance traveled by sea can be traveled by road causing the same amount of combined $\mathrm{NO}_{\mathrm{x}}, \mathrm{SO}_{2}$, and $\mathrm{PM}$ emissions.

The results show the larger footprint of road in terms of $\mathrm{CO}_{2}$ emissions and the still larger footprint of SSS in terms of the other air pollutants. As regards $\mathrm{CO}_{2}$, it has been shown that short sea shipping coupled to road haulage and inland waterways is much preferable to road haulage (from Portugal) for most coastal NUTS 2 regions, while railbased transport chains (sometimes combined with SSS) are more appropriate for inland NUTS 2 regions. The potential for reducing GHG transport emissions by shifting to intermodal chains in this corridor is clear and becomes more relevant when emission abatement technologies and cleaner fuels are used. The results also show that intermodal solutions making use of rail can be very competitive in this corridor, but the compatibility of railway lines between Portugal and Spain and other countries is still an issue. This numerical tool for emissions assessment is part of a broader external costs tool (based in the same transportation network model) that is still under development. Further work will be published on that matter.

Supplementary Materials: The following are available online at https: / www.mdpi.com/article / 10.3390/jmse9060679/s1, Table S1: Vehicle characteristics and corresponding variables, Table S2: Emission factors chosen by the software SA in both emission scenarios.

Author Contributions: Conceptualization, M.M.R. and T.A.S.; methodology, M.M.R.; software and validation, M.M.R.; formal analysis, T.A.S.; investigation and resources, M.M.R. and T.A.S.; data curation, M.M.R.; writing—original draft preparation, M.M.R.; writing—review and editing, T.A.S.; visualization, M.M.R.; supervision, T.A.S.; project administration, T.A.S.; funding acquisition, T.A.S. All authors have read and agreed to the published version of the manuscript.

Funding: This research was funded by Fundação para a Ciência e a Tecnologia (FCT), grant number PTDC/ECI-TRA/28754/2017 and contributes to the Strategic Research Plan of the Centre for Marine Technology and Ocean Engineering (CENTEC), which is financed by FCT under contract UIDB/UIDP/00134/2020.

Data Availability Statement: The data presented in this study are available on request from the corresponding author.

Conflicts of Interest: The authors declare no conflict of interest. The funders had no role in the design of the study; in the collection, analyses, or interpretation of data; in the writing of the manuscript, or in the decision to publish the results.

\section{Appendix A. Emission Abatement Technologies}

Exhaust gas treatment systems such as DPFs and scrubbers are technologies for particulate and $\mathrm{SO}_{\mathrm{x}}$ reductions. DPFs simply filter the particulate matter from the exhaust. Scrubbers are systems that mix the exhaust gas and particulates with a scrubbing medium that can be either wet (WS) (fresh or salted water with additives) or dry (DS) (usually granulated hydrated lime). The scrubbing medium absorbs and dissolves the pollutant gases and traps particulates, which are finally converted into benign compounds or filtered from the washwater in the case of wet scrubbers. 
Selective catalytic reduction (SCR) is an exhaust treatment system that consists of the injection of a reducing agent into the exhaust gas and through a catalyst converting the $\mathrm{NO}_{\mathrm{x}}$ to nitrogen and water. This technology is more efficient for higher exhaust temperatures, and this justifies why its application to slow speed engines that are more efficient and have lower exhaust temperatures is less common. However, it is possible to introduce modifications that allow the catalyst to be exposed to the required higher exhaust temperatures. The sulfur content of the fuel impacts the effectiveness and the life of the catalyst, so usually, it is specified to use low sulfur content fuels or upstream scrubbers that filter the air before it passes through the catalytic elements [25].

Exhaust gas recirculation (EGR) consists of the recirculation of a fraction of the exhaust gases, which are filtered, cooled, and sent back to the engine charge air. This process lowers the combustion temperature and therefore the quantity of $\mathrm{NO}_{\mathrm{x}}$. It has been applied to twostroke marine diesel engines and is being explored for medium and high-speed engines. EGR efficiency when using fuels with higher sulfur contents is challenged by the problem of corrosion of the system's components due to sulfuric acid formation. To reduce corrosion, the EGR system usually includes a scrubber that filters the recirculated exhaust from $\mathrm{SO}_{\mathrm{x}}$ and PM before it is mixed with the combustion air, which means that it can be used along with higher sulfur content fuels. Nevertheless, only the recirculated part of the exhaust gas is cleaned in the upstream scrubber, and so, the EGR system can be combined with a downstream scrubber system to further reduce the total $\mathrm{SO}_{\mathrm{x}}$ emissions $[25,31,42]$.

HAM needs to be integrated with the engine, and it works on the same principle of EGR-lowering the combustion temperature and thereby reducing $\mathrm{NO}_{\mathrm{x}}$ formation-by injecting seawater in the combustion air. It has been tested on both small high-speed engines as well as on larger engines such as the one in the passenger ferry MS Mariella [42].

The same principle is applied by the WIF technique. Water is added and emulsified to the fuel to lower the combustion temperature and thereby reduce the formation of $\mathrm{NO}_{\mathrm{x}}$. Comparing to HAM, the difference is whether water is mixed with the combustion air or the fuel, and in both cases, the result is water vapor replacing part of the combustion air $[31,43]$. WIF has been tested in slow two-stroke diesel engines using residual fuel oils. Due to the difference in the properties of residual and distillate fuels, emulsification with water in the case of the latter requires the use of a suitable emulsifier for the quantity of water being mixed into the fuel [44].

\section{Notes}

1 http:/ / mae-project.eu/ (accessed on 21 June 2021).

\section{References}

1. European Commission, Secretariat-General. Communication from the Commission to the European Parliament, the Council, the European Economic and Social Committee and the Committee of the Regions an European Strategy for Low-Emission Mobility; European Commission: Brussels, Belgium, 2016.

2. United Nations. Adoption of the Paris Agreement. In Proceedings of the Conference of the Parties, Twenty-first session, Paris, France, 30 November-11 December 2015.

3. European Commission, Secretariat-General. Communication from the Commission to the European Parliament, European Council, the Council, the European Economic and Social Committee and the Committee of the Regions the European Green Deal; European Commission: Brussels, Belgium, 2019.

4. European Parliament, Council of the European Union. Directive (EU) 2016/2284 of the European Parliament and of the Council of 14 December 2016 on the reduction of national emissions of certain atmospheric pollutants, amending Directive 2003/35/EC and repealing Directive 2001/81/EC (Text with EEA relevance). Off. J. Eur. Union 2016, No L 36, 1-31.

5. EEA. Evaluation of Progress under the EU National Emission Ceilings Directive-Progress towards EU Air Quality Objectives; EEA Technical Report No 14/2012; European Environment Agency: Copenhagen Denmark, 2012.

6. European Commision. Transport 2050: The Major Challenges, the Key Measures; MEMO/11/197; European Commission: Brussels, Belgium, 2011.

7. Hjelle, H.M. Short Sea Shipping's Green Label at Risk. Transp. Rev. 2010, 30, 617-640. [CrossRef]

8. Kim, N.S.; Van Wee, B. Toward a Better Methodology for Assessing $\mathrm{CO}_{2}$ Emissions for Intermodal and Truck-only Freight Systems: A European Case Study. Int. J. Sustain. Transp. 2013, 8, 177-201. [CrossRef] 
9. Deniz, C.; Durmuşoğlu, Y. Estimating shipping emissions in the region of the Sea of Marmara, Turkey. Sci. Total. Environ. 2008, 390, 255-261. [CrossRef]

10. Raza, Z.; Svanberg, M.; Wiegmans, B. Modal shift from road haulage to short sea shipping: A systematic literature review and research directions. Transp. Rev. 2020, 40, 382-406. [CrossRef]

11. Contini, D.; Merico, E. Recent Advances in Studying Air Quality and Health Effects of Shipping Emissions. Atmosphere 2021, 12, 92. [CrossRef]

12. Spoof-Tuomi, K.; Niemi, S. Environmental and Economic Evaluation of Fuel Choices for Short Sea Shipping. Clean Technol. 2020, 2, 34-52. [CrossRef]

13. Miola, A.; Ciuffo, B.; Giovine, E.; Marra, M. Regulating Air Emissions from Ships: The State of the Art on Methodologies, Technologies and Policy Options; Publications Office of the European Union: Luxembourg, 2010.

14. Moreno-Gutiérrez, J.; Calderay, F.; Saborido, N.; Boile, M.; Valero, R.R.; Durán-Grados, V. Methodologies for estimating shipping emissions and energy consumption: A comparative analysis of current methods. Energy 2015, 86, 603-616. [CrossRef]

15. Jalkanen, J.-P.; Brink, A.; Kalli, J.; Pettersson, H.; Kukkonen, J.; Stipa, T. A modelling systems for the exhaust emissions of marine traffic and its application in the Baltic Sea area. Athmosperic Chem. Phys. 2009, 9, 9209-9223. [CrossRef]

16. Yau, P.S.; Lee, S.C.; Corbett, J.J.; Wang, C.; Cheng, Y.; Ho, K.F. Estimation of exahust emissions from ocean-goin vessels in Hong Kong. Sci. Total Environ. 2012, 431, 299-306. [CrossRef] [PubMed]

17. Li, C.; Yuan, Z.; Ou, J.; Fan, X.; Ye, S.; Xiao, T.; Shi, Y.; Huang, Z.; Ng, S.K.; Zhong, Z.; et al. An AIS-based high-resolution ship emission inventor and its uncertainty in Pearl River Delta region, China. Sci. Total Environ. 2016, 573, 1-10. [CrossRef] [PubMed]

18. Moreno-Gutiérrez, J.; Durán-Grados, V. Calculating ships' real emissions of pollutants and greenhouse gases: Towards zero uncertainties. Sci. Total. Environ. 2021, 750, 141471. [CrossRef] [PubMed]

19. Santos, T.A.; Ramalho, M.M.; Soares, C.G. Sustainability in short sea shipping-based intermodal transport chains. In Short Sea Shipping in the Age of Sustainable Development and Information Technology; Routledge: London, UK, 2020; pp. 89-115.

20. Faber, J.; Hanayama, S.; Zhang, S.; Pereda, P.; Comer, B.; Hauerhof, E.; van der Loeff, W.S.; Smith, T.; Zhang, Y.; Kosaka, H.; et al. Fourth IMO GHG Study: Final Report; CE Delft: Delft, The Netherlands, 2020.

21. Council of the European Union. Council Directive 88/77/EEC of 3 December 1987 on the approximation of the laws of the Member States relating to the measures to be taken against the emission of gaseous pollutants from diesel engines for use in vehicles. Off. J. 1987, 36, 33-61.

22. European Parliament, Council of the European Union. Directive 2009/30/EC of the European Parliament and of the Council of 23 April 2009 amending Directive 98/70/EC as regards the specification of petrol, diesel and gas-oil and introducing a mechanism to monitor and reduce greenhouse gas emissions (...). Off. J. Eur. Union 2009, L 140, 88-113.

23. European Parliament, Council of the European Union. Regulation (EU) 2019/1242 of the European Parliament and of the Council of 20 June 2019 setting $\mathrm{CO}_{2}$ emission performance standards for new heavy-duty vehicles and amending Regulations (EC) No 595/2009 and (EU) 2018/956 of the European Parliament (...). Off. J. Eur. Union 2019, L 198, 202-240.

24. European Parliament, Council of the European Union. Directive 97/68/EC of the European Parliament and of the Council of 16 December 1997 on the approximation of the laws of the Member States relating to measures against the emission of gaseous and particulate pollutants from internal combustion (...). Off. J. Eur. Communities 1998, L 59, 1-86.

25. Exhaust Gas Cleaning Systems Association. Association. A Practical Guide to Exhaust Gas Cleaning Systems for the Maritime Industry. In EGCSA Handbook; Sustainable Maritime Solutions Ltd.: Rotterdam, The Netherlands, 2012.

26. European Parliament, Council of the European Union. Directive (EU) 2016/802 of the European Parliament and of the Council of 11 May 2016 relating to a reduction in the sulphur content of certain liquid fuels. Off. J. Eur. Union 2016, L 132, 58-78.

27. European Parliament, Council of the European Union. Consolidated text: Regulation (EU) 2016/1628 of the European Parliament and of the Council of 14 September 2016 on requirements relating to gaseous and particulate pollutant emission limits and type-approval for internal combustion engines for (...). Off. J. Eur. Communities 2020, L252, 53-117.

28. Lloyd's Register Marine. Your Options for Emissions Compliance-Guidance for Shipowners and Operators on the Annex VI SOx and NOx Regulations; Lloyd's Register Marine: London, UK, 2015.

29. Babicz, J. Wärtsilä Encyclopedia of Ship Technology, 2nd ed.; Wärtsilä Corporation: Helsinki, Finland, 2015.

30. DNV GL. Maritime Forecast to 2050-Energy Transition Outlook 2019; DNV GL: Oslo, Norway, 2019.

31. Jordal-Jørgensen, J.; COWI. Reducing Air Pollution from Ships-A Cost Benefit Analysis and Feasibility Study on Possible Means for Further Reduction of Emissions; Environmental Project no. 1421, 2012; Miljøstyrelsen: Copenhagen, Denmark, 2012.

32. Kristensen, H.O. Analysis of Technical Data of Ro-Ro Ships; Project no. 2014-122: Mitigating and reversing the side-effects of environmental legislation on Ro-Ro shipping in Northern Europe; DTU: Copenhagen, Denmark, 2016.

33. Kristensen, H.O. Statistical Analysis and Determination of Regression Formulas for Main Dimensions of Container Ships based on IHS Fairplay Data; Project no. 2010-56; DTU: Copenhagen, Denmark, 2013.

34. Whall, C.; Cooper, D.; Archer, K.; Twigger, K.; Thruston, N.; Ockwell, D.; McIntyre, A.; Ritchie, A. Quantification of emissions from ships associated with ship movements between ports in the European Community. In Final Report; Entec UK Limited: London, UK, 2002.

35. Vierth, I.; Merkel, A. Internalization of external and infrastructure costs related to maritime transport in Sweden. Res. Transp. Bus. Manag. 2020, 100580. [CrossRef] 
36. EPA. Regulatory Impact Analysis: Control of Emissions of Air Pollution from Category 3 Marine Diesel Engines; EPA: Frankfurt, Germany, 2009.

37. EcoTransIT World Initiative (EWI). Ecological Transport Information Tool for Worldwide Transports, Methodology and Data Update 2019; IVE mbH: Hannover, Germany, 2019.

38. EEA. EMEP/EEA Air Pollutant Emission Inventory Guidebook 2019; Publications Office of the European Union: Luxembourg, 2019.

39. Rodríguez, F.; Delgado, O.; Muncrief, R. Briefing: Fuel Consumption Testing of Tractor-Trailers in the European Union and the United States. 2018. Available online: https://theicct.org/sites/default/files/publications/EU_HDV_Testing_BriefingPaper_20 180515a.pdf (accessed on 25 January 2021).

40. CE Delft. Handbook on the External Costs of Transport Version 2019-1.1; CE Delft for the European Commission, Directorate-General for Mobility and Transport: Delft, Netherlands, 2019. [CrossRef]

41. Santos, T.A.; Guedes Soares, C. Modeling transportation demand in short sea shipping. Marit. Econ. Logist. 2017, 19, 695-722. [CrossRef]

42. Entec UK Limited. Service Contract on Ship Emissions: Assignment, Abatement and Market-based Instruments Task 2b-NOx Abatement Final Report; Entec UK Limited: London, UK, 2005.

43. MAN Diesel \& Turbo. Humid Air Motor-Technology for Green Profits; MAN PrimeServ: Paris, France.

44. Andreasen, A.; Nyggard, K.B. Water-in-Fuel Emulsion as Marine Engine Fuel for Reduced NOx and Particulate Emissions; Environmental Project No. 1380 2011; Danish Environmental Protection Agency: Copenhagen, Denmark, 2011. 